\title{
LWRS ATR Irradiation Testing Readiness Status
}

Kristine Barrett

September 2012

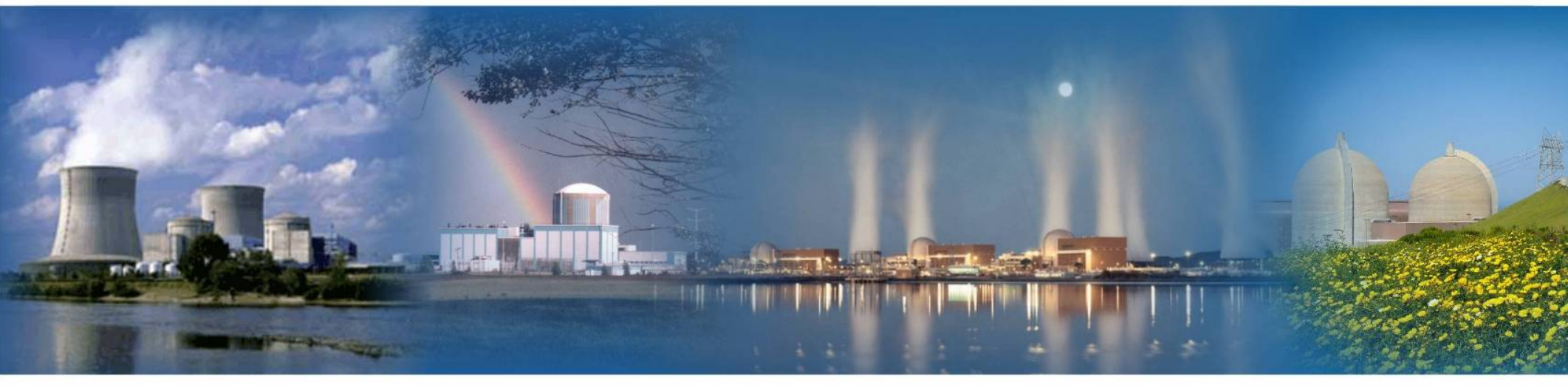

The INL is a U.S. Department of Energy National Laboratory operated by Battelle Energy Alliance 


\section{DISCLAIMER}

This information was prepared as an account of work sponsored by an agency of the U.S. Government. Neither the U.S. Government nor any agency thereof, nor any of their employees, makes any warranty, expressed or implied, or assumes any legal liability or responsibility for the accuracy, completeness, or usefulness, of any information, apparatus, product, or process disclosed, or represents that its use would not infringe privately owned rights. References herein to any specific commercial product, process, or service by trade name, trade mark, manufacturer, or otherwise, does not necessarily constitute or imply its endorsement, recommendation, or favoring by the U.S. Government or any agency thereof. The views and opinions of authors expressed herein do not necessarily state or reflect those of the U.S. Government or any agency thereof. 
INL/EXT-12-27089

\title{
LWRS ATR Irradiation Testing Readiness Status
}

Kristine Barrett

September 2012

\section{Idaho National Laboratory \\ Idaho Falls, Idaho 83415}

http://www.inl.gov

\author{
Prepared for the \\ U.S. Department of Energy \\ Office of Nuclear Energy \\ Under DOE Idaho Operations Office \\ Contract DE-AC07-05ID14517
}




\section{DISCLAIMER}

This information was prepared as an account of work sponsored by an agency of the U.S. Government. Neither the U.S. Government nor any agency thereof, nor any of their employees, makes any warranty, expressed or implied, or assumes any legal liability or responsibility for the accuracy, completeness, or usefulness, of any information, apparatus, product, or process disclosed, or represents that its use would not infringe privately owned rights. References herein to any specific commercial product, process, or service by trade name, trade mark,

manufacturer, or otherwise, do not necessarily constitute or imply its

endorsement, recommendation, or favoring by the U.S. Government or any agency thereof. The views and opinions of authors expressed herein do not necessarily state or reflect those of the U.S. Government or any agency thereof. 


\section{EXECUTIVE SUMMARY}

Development and testing of high performance nuclear fuel cladding has been identified as a high priority to support enhanced fuel performance, reliability, and reactor safety. To achieve significant safety and fuel economic improvements in the current generation of operating Nuclear Power Plants, the LWRS Fuels Pathway is focusing on developing advanced nuclear-grade ceramic materials to improve fuel cladding performance. The high strength and low chemical reactivity of advanced ceramics may allow for higher performance nuclear fuel with increased safety margins. These advanced materials will allow revolutionary cladding performance and enhanced fuel mechanical designs; in the future these materials could be used with alternate fuel pellet designs to provide even further improvement in nuclear power plant economics, operation, and safety.

Multiple cladding technology candidates are being explored under the Light Water Reactor Sustainability (LWRS) Advanced Nuclear Fuels Pathway for further testing and development and eventual demonstration in a nuclear test reactor. Conceptual fuel rod designs will be developed for each advanced cladding option and these designs will undergo preliminary analysis and review in anticipation of developing an engineering design. Tests conducted will focus on sample coupons and short cylindrical pieces to acquire the necessary material properties and preliminary performance data. One of the technologies initially explored is an advanced fuel cladding made from ceramic matrix composites $(\mathrm{CMC})$ utilizing silicon carbide $(\mathrm{SiC})$ as an external wrap on commercial Zircaloy tubes. The preparation process for ATR readiness of the SiC CMC Zircaloy-4 (Zr-4) hybrid cladding design is presented in this report as an example and provides Lessons Learned for further development and testing of additional cladding technologies. The objectives of this report are to: 1) identify irradiation testing requirements, 2) describe the design and acceptance process for ATR safety assurance, and 3) evaluate the $\mathrm{SiC} \mathrm{CMC} \mathrm{Zr-4} \mathrm{hybrid} \mathrm{cladding} \mathrm{prototype} \mathrm{test} \mathrm{results} \mathrm{to}$ determine irradiation readiness and to identify additional testing requirements.

For the SiC CMC Zr-4 hybrid design, the design analysis, design review, and safety analysis have been completed for non-fueled, non-bonded cladding tubes (inner $\mathrm{Zr}-4$ and $\mathrm{SiC} \mathrm{CMC}$ outer overbraid tube). Mock-up tests are currently being conducted for process development and equipment operability in preparation for prototype tests required to support ATR readiness for the hybrid design cladding technology. Additional tasks to be completed prior to ATR testing of the non-fueled hybrid design and additional testing and analysis to be performed prior to fueled drop-in capsule irradiation testing of the SiC CMC Zr-4 hybrid design were identified. The processes and lessons learned identified in this report provides guidance for planning future technology demonstrations in the ATR and potentially other test reactors.

\section{ACKNOWLEDGEMENTS}

The following LWRS team members contributed to the design, safety analysis, material characterization, and ATR readiness of the SiC CMC Zr-4 hybrid tubes and should be acknowledged

for their valuable contributions to this report: Shannon Bragg-Sitton, Christopher Glass, Glenn Roth, Kelly Ellis, Michael Teague, Melissa Teague, Isabella van Rooyen, Julie Chapman, Amber Miller, Tammy Towbridge, Dave Hurely, John Garnier, George Griffith, Christopher Dahl, Susan Case, Steven Bryan, James Williams, Michael David, Tony Walters, Corey Beebe, and Adam St. Clair. 


\section{CONTENTS}

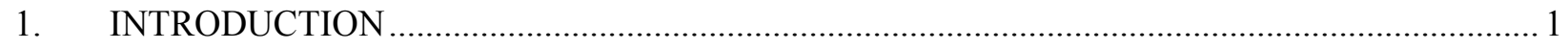

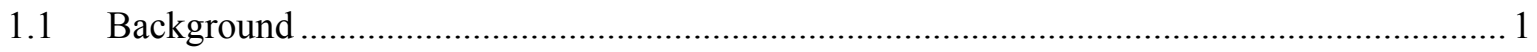

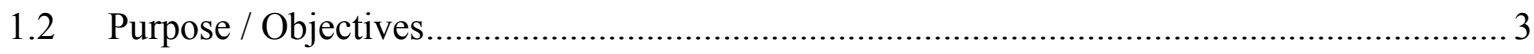

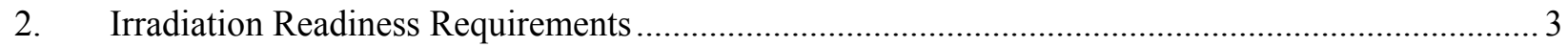

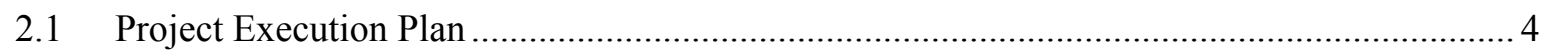

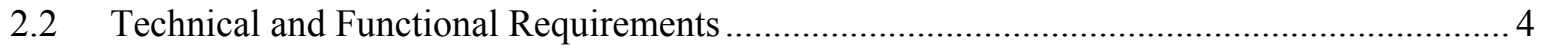

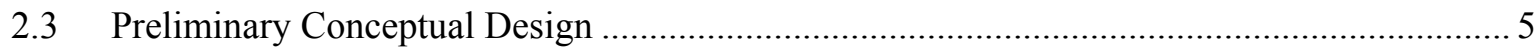

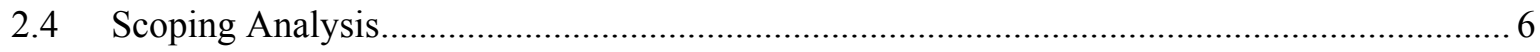

2.5 Initial Fabrication Lessons Learned ……............................................................... 7

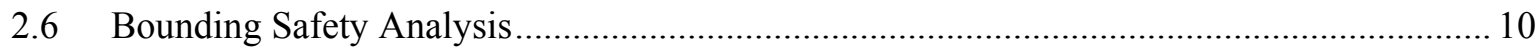

2.6.1 Stress Analysis of Bonded vs. Non-bonded SiC CMC Zr-4 Tubes .......................... 11

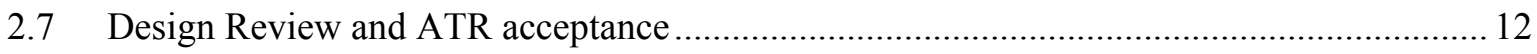

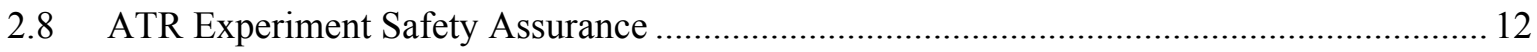

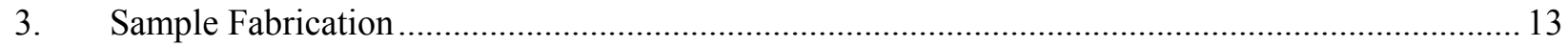

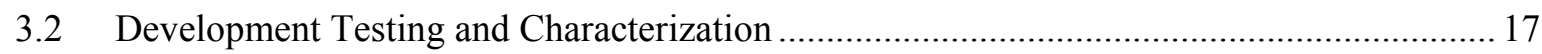

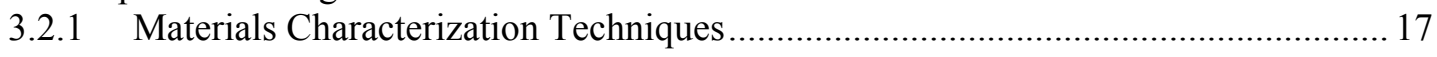

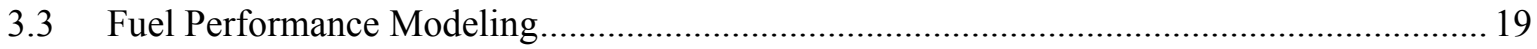

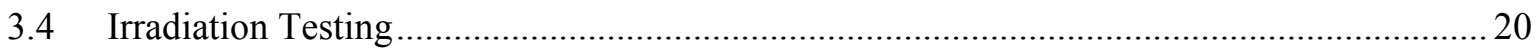

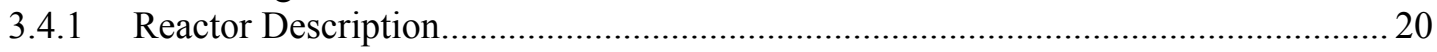

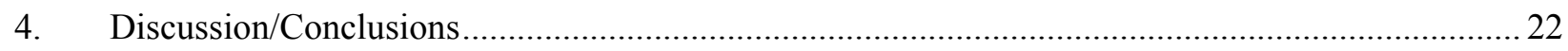

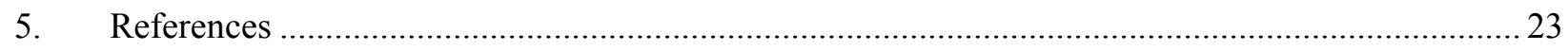

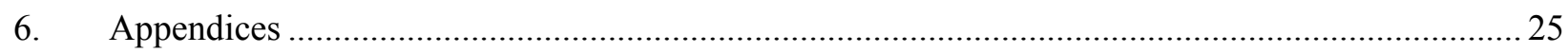




\section{FIGURES}

Figure 1. General work process for technologies selected in preparation for reactor demonstrations [2] .......... 2

Figure 2. Geometry of the LWRS rodlet assembly design for the SiC CMC Zr-4 hybrid cladding technology. A patent for this cladding rodlet concept has been submitted by the INL [3]

Figure 3. ATR readiness process flow diagram outlining major tasks required for drop-in capsule insertion readiness. Refer to the Acronyms list for definitions of PEP, T\&FR and ESAP. 4

Figure 4. LWRS-1 capsule loading plan in the small I B-L basket positions............................................... 5

Figure 5. Axial cross-section view of 3 capsules in an LWRS capsule stack within an ATR aluminum three hole basket.

Figure 6. Radial cross section view of an LWRS experiment capsule assembly. Fuel rodlet stacks are designated by location as 1,2 , or 3 . The notch is located in the basket to align with the direction toward core centerline.

Figure 7. Zircadyne tube failure during final assembly of the hybrid tube.

Figure 8. Representative SEM image of the Zr-702 tube broken edge magnified 250X.

Figure 9. SEM image of the Zr-702 tube broken edge magnified 7500X showing crack propagation in the tube.

Figure 10. Photos of the SiC CMC Zr-4 hybrid design samples fabricated to support the Hot Water Corrosion Flow and bend tests. 14

Figure 11. Example material inventory page from the LWRS Fuels Material Inventory Database.

Figure 12. Example of test classifications to be performed on fuel cladding system technologies examined under the LWRS Program. This example classification was designed specifically for a hybrid SiC CMC design; however, it can be used as a template for alternate technologies [21]

Figure 13. ATR core cross sectional diagram [22] 
TABLES 


\section{ACRONYMS}

ASTM American Society for Testing and Materials

ATR Advanced Test Reactor

CASL Consortium for Advanced Simulation of Light Water Reactors

CFR Code of Federal Regulations

CMC Ceramic Matrix Composite

DNBR Departure from Nucleate Boiling Ratio

DOE U.S. Department of Energy

DOE NE DOE Office of Nuclear Energy

ESAP Experiment Safety Assurance Package

FIR Flow Instability Ratio

FY Fiscal Year

HGR Heat Generation Rate

HWCF Hot Water Corrosion Flow

INL Idaho National Laboratory

LWR Light-Water Reactor

NEAMS Nuclear Energy Advanced Modeling and Simulation

PCS Primary Coolant System

PEP Project Execution Plan

PIE Post Irradiation Testing

PIP Polymer Impregnation and Pyrolysis

PWR Pressurized Water Reactor

QA Quality Assurance

QAPD Quality Assurance Program Document

R\&D Research and Development

SEM Scanning Electron Microscope

SiC Silicon Carbide

TEM Transmission Electron Microscope

T\&FR Technical \& Functional Requirements

U.S. United States

Zr-4 Zircaloy-4 


\section{LWRS ATR Irradiation Testing Readiness Status 1. INTRODUCTION}

The Light Water Reactor Sustainability (LWRS) Program was established by the U.S. Department of Energy Office of Nuclear Energy (DOE-NE) to develop technologies and other solutions that can improve the reliability, sustain the safety, and extend the life of the current reactors. The LWRS Program is divided into four R\&D Pathways: (1) Materials Aging and Degradation; (2) Advanced Light Water Reactor Nuclear Fuels; (3) Advanced Instrumentation, Information and Control Systems; and (4) RiskInformed Safety Margin Characterization. This report describes an irradiation testing readiness analysis in preparation of LWRS experiments for irradiation testing at the Idaho National Laboratory (INL) Advanced Test Reactor (ATR) under Pathway (2). The focus of the Advanced LWR Nuclear Fuels Pathway is to improve the scientific knowledge basis for understanding and predicting fundamental performance of advanced nuclear fuel and cladding in nuclear power plants during both nominal and offnominal conditions. This information will be applied in the design and development of high-performance, high burn-up fuels with improved safety, cladding integrity, and improved nuclear fuel cycle economics.

\subsection{Background}

Development and testing of high performance nuclear fuel cladding has been identified as a high priority to support enhanced fuel performance, reliability, and reactor safety. The standard zirconiumbased cladding currently used in operating LWRs in the United States provides a baseline performance measure for advanced fuel cladding options. To achieve significant safety and fuel economic improvements in the current generation of operating Nuclear Power Plants, the LWRS Fuels Pathway is focusing on developing advanced nuclear-grade ceramic materials to improve fuel cladding performance. The high strength and low chemical reactivity of advanced ceramics may allow for higher performance nuclear fuel with increased safety margins. These advanced materials will allow revolutionary cladding performance and enhanced fuel mechanical designs; in the future these materials could be used with alternate fuel pellet designs to provide even further improvement in nuclear power plant economics, operation, and safety.

Multiple cladding technology candidates are being explored under the LWRS Advanced Nuclear Fuels Pathway for further testing and development and eventual demonstration in a nuclear test reactor. The technology selection process and technology candidates considered are documented in an LWRS fuel cladding system Trade-off Study [1]. Final technology selections will be based on Industry/Stakeholder input, program objectives, and feasibility for further development and testing. A suite of materials characterization tests and property measurements will be conducted to fill gaps in the Cladding Technology database for the selected candidate cladding material and design. These data will, in turn, be used to refine modeling simulations of the fuel-clad system under nominal and off-nominal reactor conditions, and modeling results will be integrated with the conceptual design process. Conceptual fuel rod designs will be developed for each advanced cladding option and these designs will undergo preliminary analysis and review in anticipation of developing an engineering design. Tests conducted will focus on sample coupons and short cylindrical pieces to acquire the necessary material properties and preliminary performance data. This work, which will consider multiple technologies in parallel, will take approximately three years to complete. The general work process [2] that will be adopted for each technology investigated is illustrated in Figure 1. 


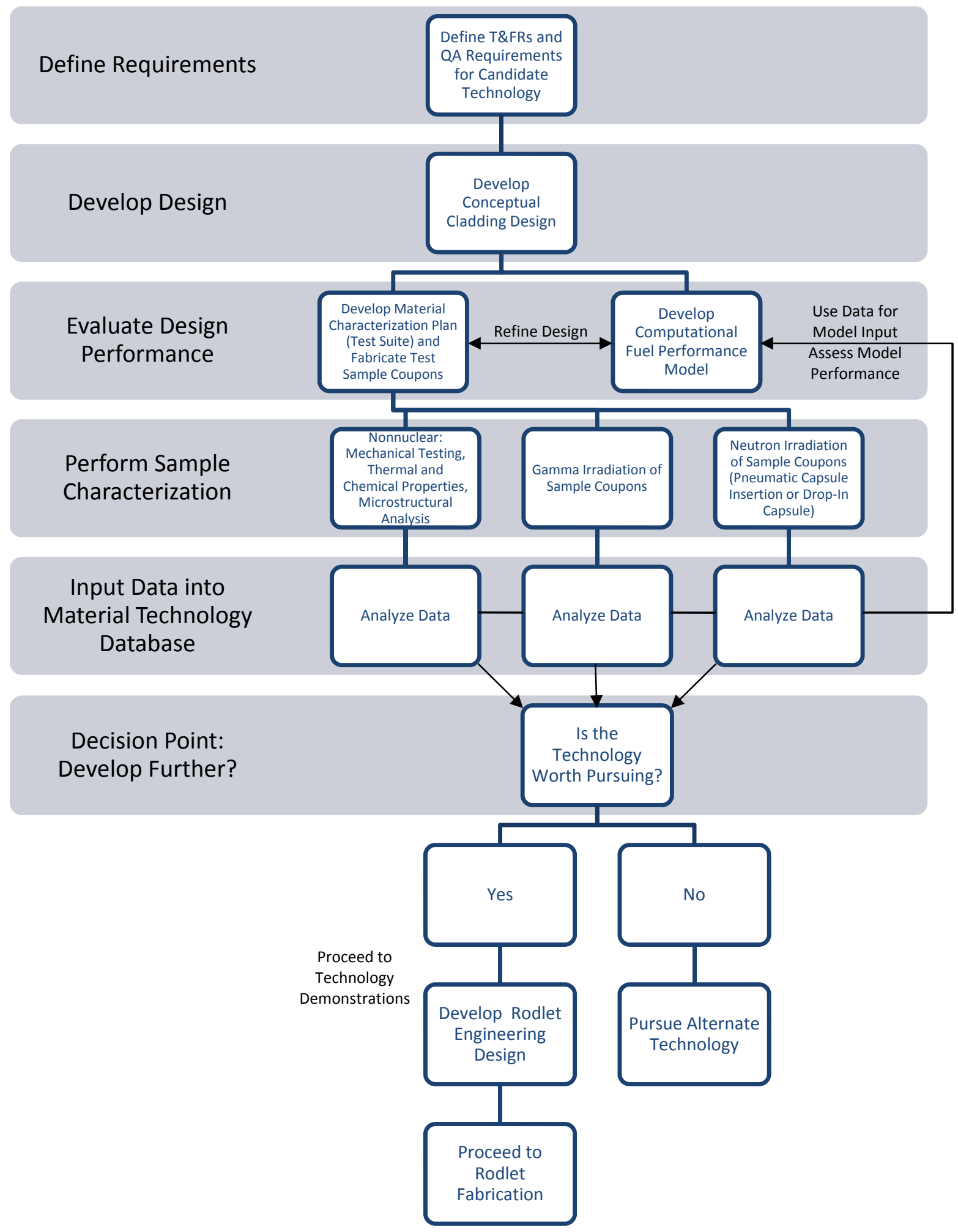

Figure 1. General work process for technologies selected in preparation for reactor demonstrations [2]. 


\subsection{Purpose / Objectives}

One of the technologies initially explored under the LWRS Advanced Nuclear Fuels Pathway (prior to the Trade-off Study) is an advanced fuel cladding made from ceramic matrix composites (CMC) utilizing silicon carbide (SiC) as an external wrap on commercial Zircaloy tubes (Figure 2). This design was originally selected for preliminary ATR irradiation testing of a scaled-down version of an LWR fuel rod to obtain a better understanding of $\mathrm{SiC} \mathrm{CMC} \mathrm{cladding} \mathrm{performance} \mathrm{under} \mathrm{irradiation} \mathrm{conditions.} \mathrm{SiC}$ $\mathrm{CMC}$ is a promising technology for nuclear applications because it is a high temperature ceramic material that is also chemically nonreactive. Very fine fibers of silicon carbide (SiC) are woven into a tubular cladding form that is embedded in a $\mathrm{SiC}$ matrix. The combination of $\mathrm{SiC}$ fibers embedded in a $\mathrm{SiC}$ matrix provides greater structural strength than if the matrix is used alone. The preparation process for ATR readiness of the SiC CMC Zircaloy-4 (Zr-4) hybrid cladding design is presented in this report as an example and provides Lessons Learned for candidate technologies identified in the Trade-Off Study. The objectives of this report are to: 1) identify irradiation testing requirements, 2) describe the design and acceptance process for ATR safety assurance, and 3) evaluate the SiC CMC Zr-4 hybrid cladding prototype test results to determine irradiation readiness and to identify additional testing requirements.

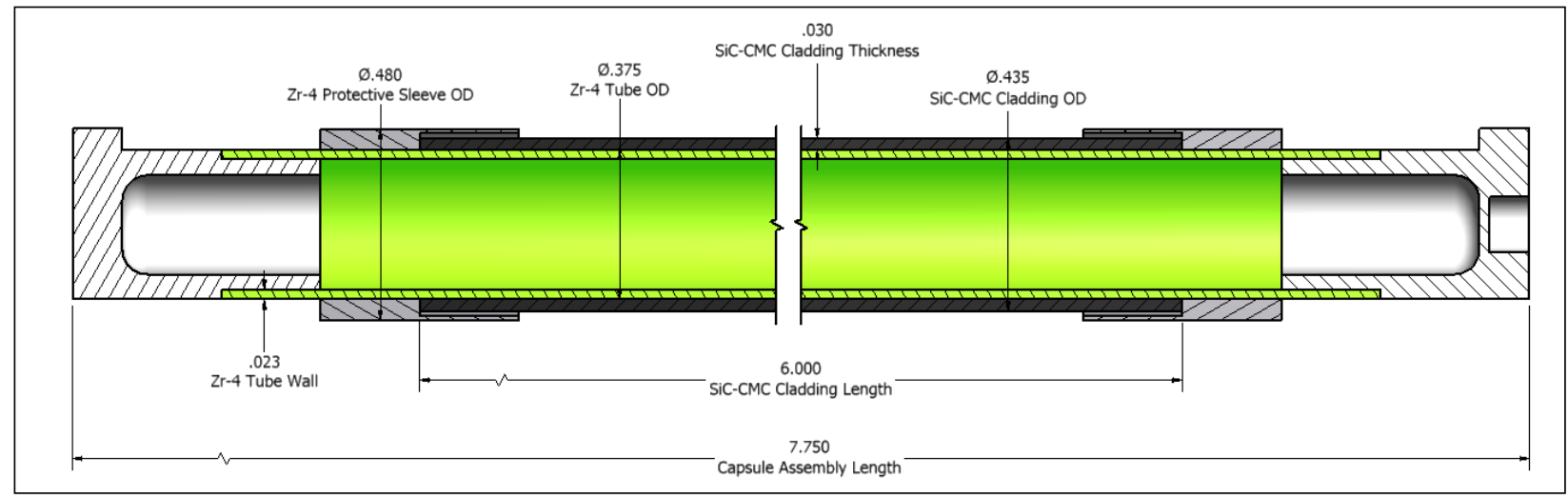

Figure 2. Geometry of the LWRS rodlet assembly design for the SiC CMC Zr-4 hybrid cladding technology. A patent for this cladding rodlet concept has been submitted by the INL [3].

\section{Irradiation Readiness Requirements}

Figure 3 shows the experiment preparation process flow diagram outlining requirements for insertion readiness of drop-in capsule experiments to be irradiated at the Idaho National Laboratory (INL) Advanced Test Reactor (ATR). This process should be followed for all drop-in capsule experiments to be irradiated at the ATR. Drop-in capsule tests cost much less than either instrumented-lead or loop tests, but provide less flexibility and no dynamic control of the irradiation environment. However, drop-in capsule experiments can provide rapid and valuable results to better understand innovative fuel and cladding performance. 


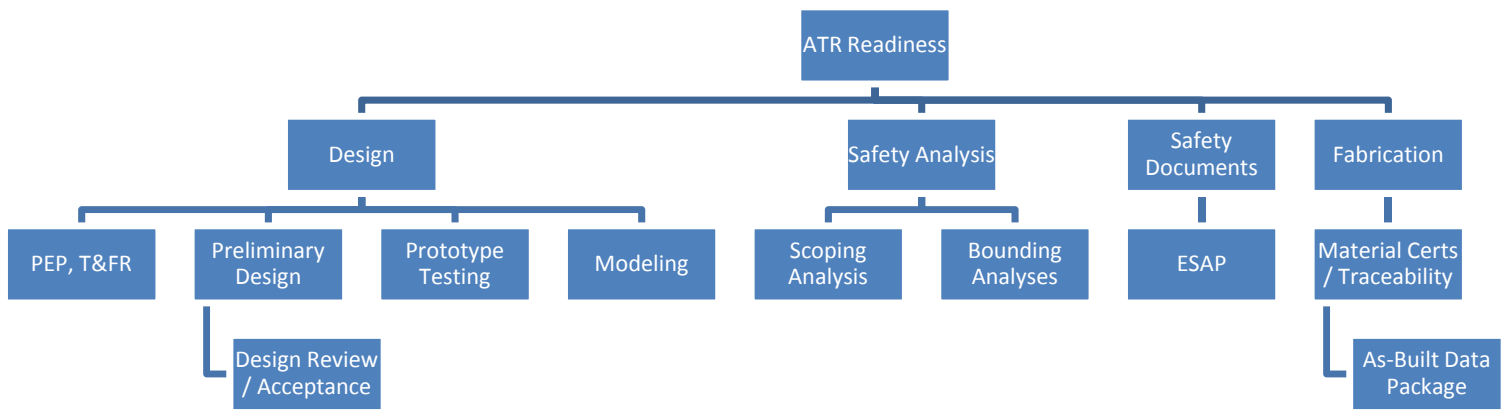

Figure 3. ATR readiness process flow diagram outlining major tasks required for drop-in capsule insertion readiness. Refer to the Acronyms list for definitions of PEP, T\&FR and ESAP.

\subsection{Project Execution Plan}

INL requires that a Project Execution Plan (PEP) be generated for the life-cycle of all irradiation testing experiments. The PEP applies to the ATR irradiation testing portion of the project mission along with all associated prototype tests, fabrication, assembly, and post irradiation examination (PIE) activities [4]. The PEP for the LWRS Fuels Pathway experiments is documented in PLN-3971 [5]. PLN-3971 describes how the experiment will be conducted for the initiation, execution, and the closeout phases of the experiment. The PEP includes a description of design and analysis requirements, configuration management, quality control, transport plans, PIE plans, and waste disposition. The PEP also includes a project team interface/responsibility matrix and roles and responsibilities for principal team members. LWP-10700 requires that the PEP be updated annually, at a minimum, to ensure that scope creep is captured and that project supporting documents are identified as the project progresses.

\subsection{Technical and Functional Requirements}

The Technical and Functional Requirements (T\&FR) document includes safety compliance requirements and LWRS program specific design requirements for the design of R\&D drop-in capsule experiment components to be irradiated in the ATR. Technical and functional requirements should be written by the principal investigators and/or program leads to clearly identify fabrication requirements for each technology being tested to meet facility safety, quality, and program requirements. The T\&FRs will include fabrication codes and standards, cleanliness standards, design analysis requirements, test requirements, and inspection criteria. Technical and functional requirements for fabrication by vendors, universities, or subcontractors will be included in the contract Statement of Work (SOW). In addition to the challenges associated with material and dimensional properties of the experiment assembly, neutronic and thermal hydraulic design compatibility must be taken into account in defining the technical and functional requirements for a conceptual cladding design. In moving forward to the rodlet conceptual and engineering designs, the design must take into account a variety of challenges for in-reactor demonstrations.

The T\&FRs for the LWRS irradiation testing experiments have been established and placed under configuration control in the INL Electronic Document Management System in accordance with LWP1201 [6]. The T\&FR [7] contains those technical and functional Safety Assurance and Programmatic requirements associated with the LWRS experiment design and analysis. 


\subsection{Preliminary Conceptual Design}

The conceptual design refers to the overall design for the fuel cladding including geometric details such as cladding thickness, inner / outer diameter, overall length, and end-cap design in addition to fabrication details, such as the overall cladding composition, layering techniques (e.g. SiC CMC and monolithic $\mathrm{SiC}$, or $\mathrm{SiC} \mathrm{CMC}$ with a metallic liner), fabrication methods and processing techniques. This conceptual design is used in the preliminary scoping analyses that will assess the expected performance potential for the proposed cladding design. The design concept for the SiC CMC Zr-4 hybrid tubes was developed at the INL and an Invention Disclosure Request (IDR) was submitted in 2010 [IDR number BA-477, (3)]. A patent was later submitted in 2011 by INL on the design concept. The design concept was further refined to utilize existing ATR hardware (i.e., a B-L three-hole basket to house the rodlets during irradiation in the reactor core for insertion in the small I and large B positions [8]). An example of how the LWRS-1 capsules will be loaded in the ATR aluminum baskets is shown in Figure 4. The basket design for the fueled (LWRS-2) experiments will be similar to the ATR B three-hole basket, but designed with a single annulus rather than a three-hole design to increase the basket annulus between the fueled capsules and the basket. All future LWRS experiment assemblies will be designed to fit inside the baskets such that there is adequate coolant circulation to prevent temperature distortions or mechanical effects, and that there is adequate mechanical support to secure the experiment assembly throughout the processes of reactor insertion, irradiation, and removal from the reactor.

\section{LWRS-1 EXPERIMENT ATR POSITION I-23 LOADING DIAGRAM}
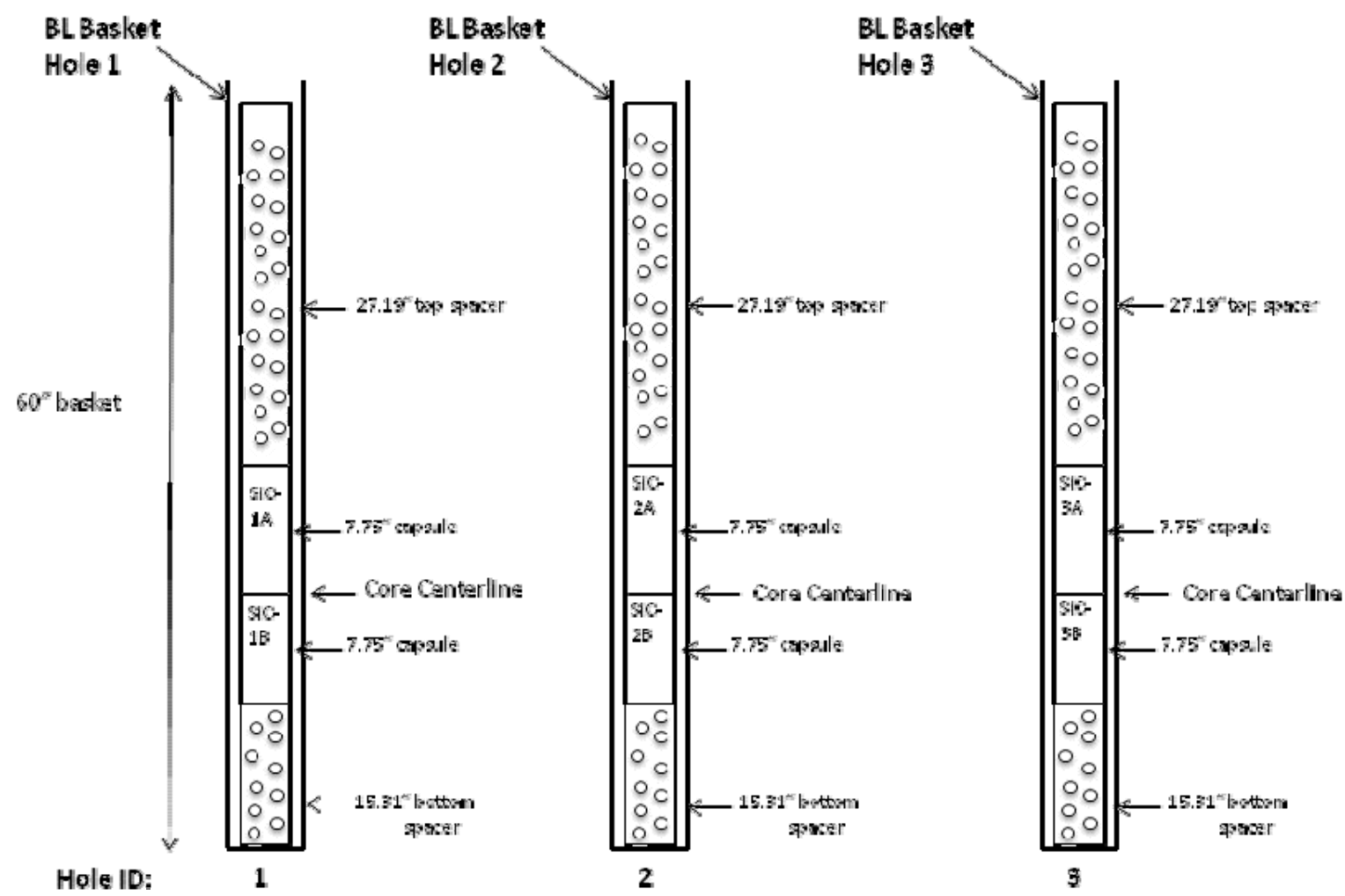

Figure 4. LWRS-1 capsule loading plan in the small I B-L basket positions.

The conceptual design for the SiC CMC Zr-4 hybrid cladding rodlet was based on previous mixed oxide (MOX) experiments performed at the INL ATR in the small I positions. The design utilizes an 
aluminum 3-hole basket in which three (3) 7-inch rodlets are stacked in each of the 3 basket holes [Figure 5].

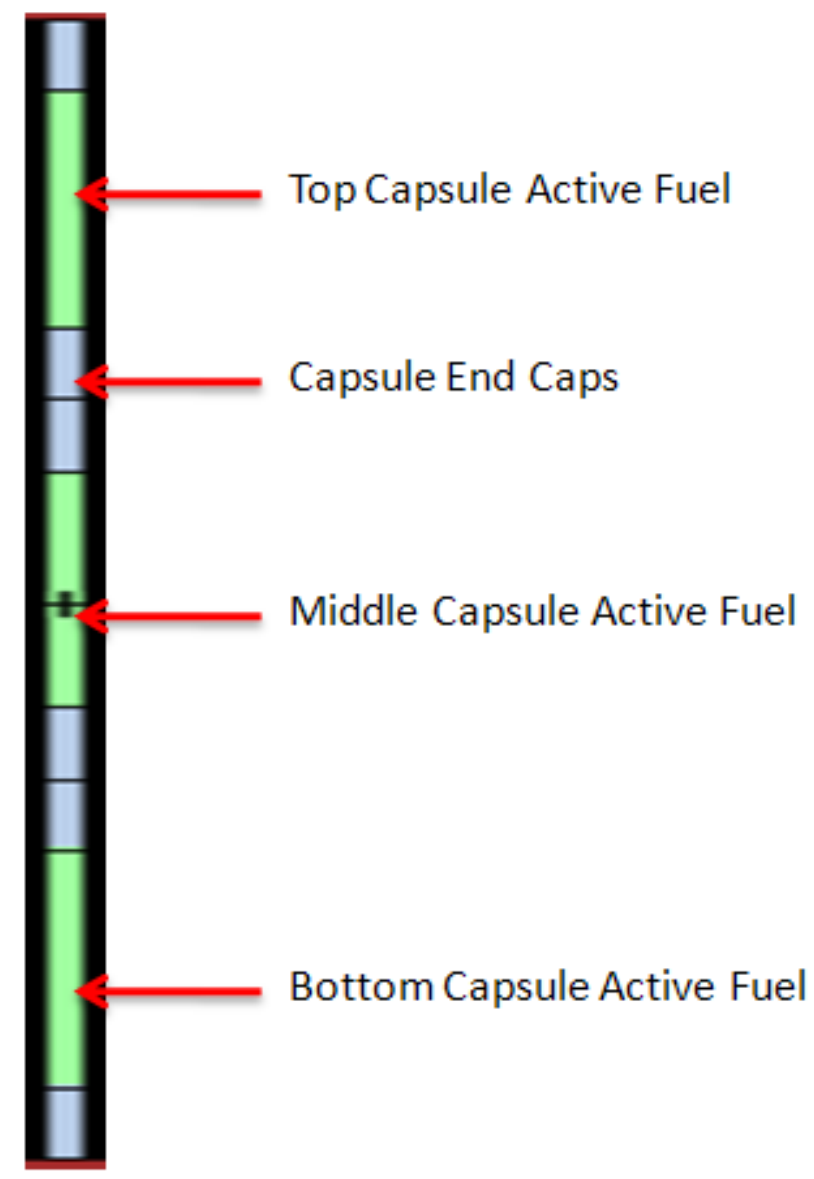

Figure 5. Axial cross-section view of 3 capsules in an LWRS capsule stack within an ATR aluminum three hole basket.

\subsection{Scoping Analysis}

The intent of the scoping analysis is to identify irradiation positions in the ATR and optimum irradiation conditions based on the conceptual design and program objectives. Results from the scoping analysis may be used to refine the conceptual design if the irradiation position and/or conditions do not meet program objectives. A neutronics scoping analysis was performed for the SiC CMC Zr-4 hybrid conceptual design [9] prior to sample fabrication and prototype testing to determine if the conceptual design was sufficient to meet the program irradiation objectives. A design target of $10 \mathrm{~kW} / \mathrm{ft}$ was used with a goal of having the flexibility to go up to $12 \mathrm{~kW} / \mathrm{ft}$ if desired. Table 1 shows the minimum and maximum Linear Heat Generation Rates (LHGRs) for 5 different enrichments in 3 different ATR test positions (B9, B11 and I23). 
Table 1: Minimum and Maximum LHGR in $\mathrm{kW} / \mathrm{ft}$ for B9, B11, and I23 positions

\begin{tabular}{|cccccc|}
\hline Enrichment & B9 Max & B9 Min & B11 Max & B11 Min & I23 Max \\
\hline $1 \%$ & 4.72 & 2.34 & 5.46 & 2.72 & - \\
$2 \%$ & 8.45 & 4.11 & 9.80 & 4.76 & - \\
$3 \%$ & 11.56 & 5.51 & 13.39 & 6.39 & - \\
$4 \%$ & 14.24 & 6.67 & 16.45 & 7.68 & - \\
$5 \%$ & 16.54 & 7.62 & 19.07 & 8.80 & 11.55 \\
\hline
\end{tabular}

Assuming a maximum enrichment of $5 \mathrm{wt} \% \mathrm{U} 235$ (for a fueled rodlet scenario), the B11 position was found to provide the greatest flexibility in achieving the highest powers possible in all 9 fuel samples with enrichment being limited in order to stay below the estimated $12 \mathrm{~kW} / \mathrm{ft}$ limit of the existing basket design. The B9 position could also achieve the program goals with only a decrease in the powers of the pins in stack 2 (see Figure 6). The I23 position is not capable of producing $12 \mathrm{~kW} / \mathrm{ft}$ even at $5 \% \mathrm{U} 235$ enrichment (therefore a minimum LHGR in not listed in Table 1); however, for a non-fueled cladding only irradiation test, the I23 position is a viable experiment location.

\section{POSTION I-23 BASKET ORIENTATION}

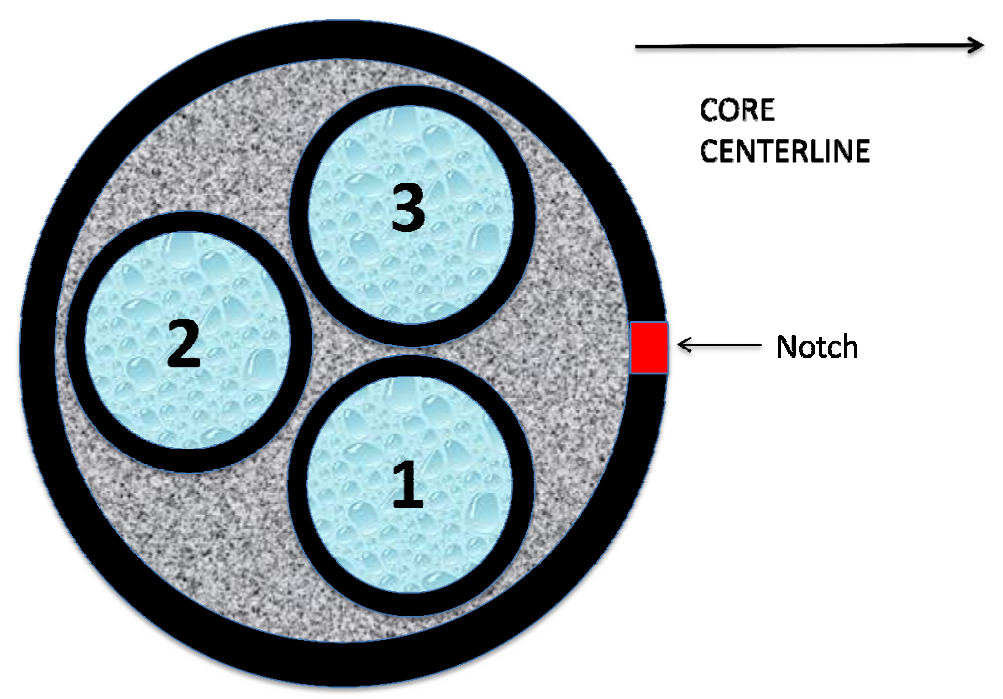

Figure 6. Radial cross section view of an LWRS experiment capsule assembly. Fuel rodlet stacks are designated by location as 1,2 , or 3 . The notch is located in the basket to align with the direction toward core centerline.

\subsection{Initial Fabrication Lessons Learned}

A lesson learned from the SiC CMC Zr-4 hybrid cladding preliminary design was failure in the bonding technique that embrittled the inner Zircodyne (Zr--702) tube, used as the liner material for the initial tubes fabricated, preventing the rodlets from being used for further testing. The intent was to chemically bond the braided outer tube fabricated from Hi-Nicalon Type S SiC fiber to the inner $\mathrm{Zr}$ 702 tubing during polymer impregnation and pyrolysis (PIP) processing used to form the $\mathrm{SiC}$ matrix around the fiber braid. The fabrication approach was built on the principle that the $\mathrm{Zr}-702$ inner tube 
could be used as the mandrel during the SiC-CMC PIP processing. There was some concern about Zircadyne oxidation at the high temperatures required for PIP processing; however, it was initially believed by the fabrication Principal Investigator (PI) that by purging the furnaces with Argon during processing, minimal oxygen would be available to oxidize the $\mathrm{Zr}-702$ tubes. This assumption proved to be incorrect, resulting in embrittled Zircodyne due to oxidation.

The outer $\mathrm{SiC}$ tubes were fabricated at Hypertherm Inc. by weaving SiC Hi-Nicalon Type S fibers together in a tri-axial weave (similar to a braid with a third set of fibers running axial through the braid) followed by formation of a very thin (sub micron) interface pyrolytic carbon (PyC) debond interlayer deposited for the purpose of transferring mechanical load within and through the ceramic fiber reinforced CMC. The sleeves were shipped to INL where they were slipped over the Zr-702 tubes (fabricated per INL drawing number 602812) and shipped to Physical Sciences Inc. (PSI) for final PIP processing. During the PIP process, the coupled tubes were coated with a polymer infused with $\mathrm{SiC}$ powder then pyrolysis heat treated at high temperature $\left(\sim 1350{ }^{\circ} \mathrm{C}\right)$ and repeated multiple cycle times $(\sim 10$ cycles $)$ per PSI's established procedures.

The SiC-CMC-Zr-702 hybrid tubes were shipped back to INL after PIP processing where they were to be assembled per INL drawing 602812. As the INL machinist attempted final assembly of the tubes by attaching the protective sleeves and the end caps (a tight interference fit) the Zircodyne portion of the tube shattered (Figure 7). Closer examination of the Zircodyne using the Scanning Electron Microscopy (SEM) indicated that the Zr-702 had reacted with oxygen at high temperatures during PIP processing (Error! Reference source not found.). Figure 9 shows crack propagation in the Zircadyne tube. Cracking most likely occurred due to oxidation and Zircadyne phase transformation during high temperature heat treatment. Further investigation is needed to determine primary cause of failure.

Plans to oxidize the Zr-4 end caps (to prevent galvanic corrosion reactions between the end cap "nubs" and the aluminum ATR basket) and the use of the Zr-alloy tube as the mandrel during PIP processing were aborted due to this failure. In addition, metallurgical examination of the weld fracture during weld qualification showed a thick oxidation layer as the cause of cracking during welding. The $\mathrm{SiC}-\mathrm{CMC}$ fabrication process was redesigned to use an inert mandrel (alumina) in place of the Zr-based tubing during PIP processing. This decision, however, eliminated the bond between the SiC CMC and the Zr-alloy inner tube. 


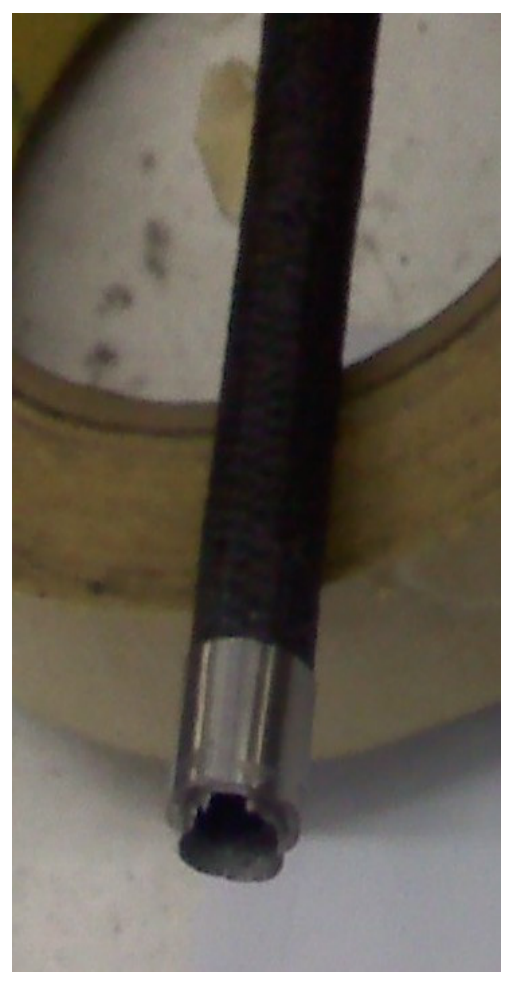

Figure 7. Zircadyne tube failure during final assembly of the hybrid tube.

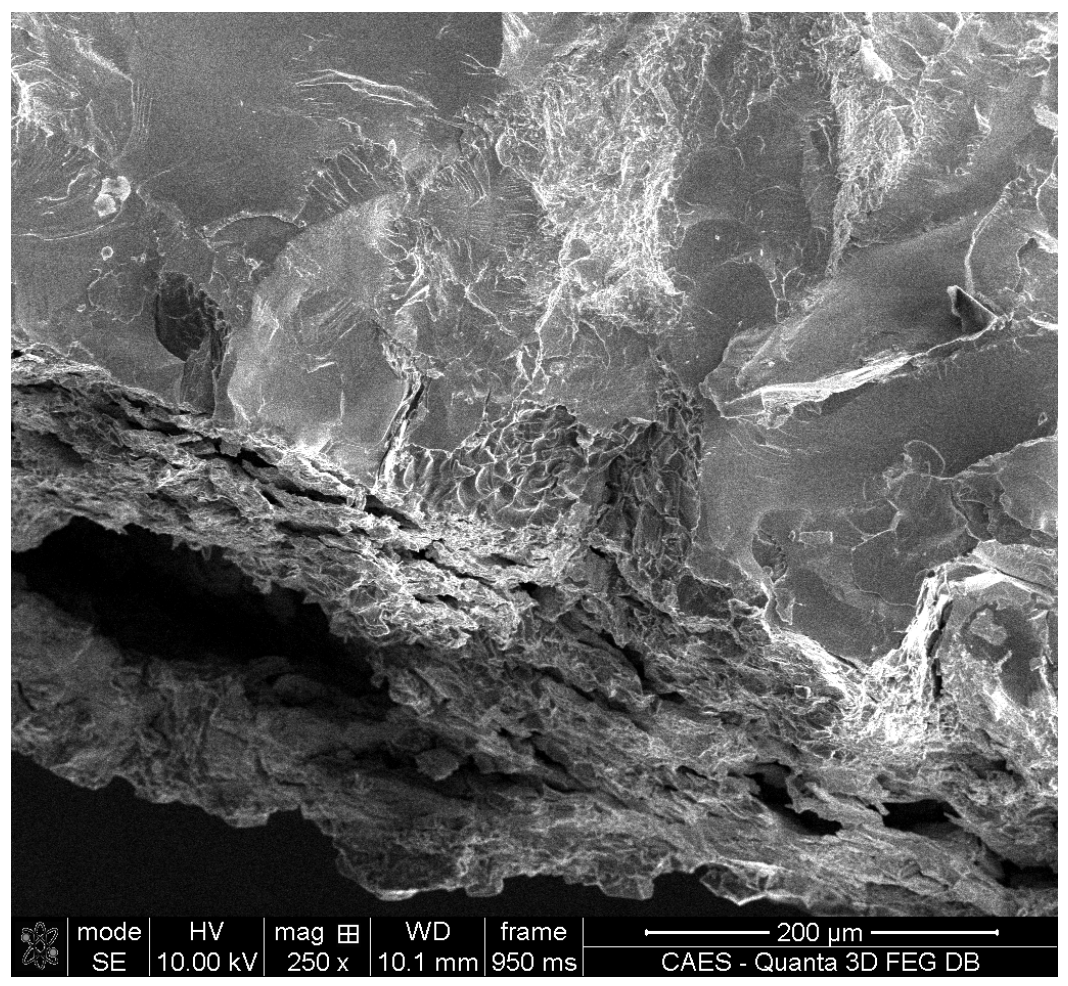

Figure 8. Representative SEM image of the Zr-702 tube broken edge magnified 250X. 


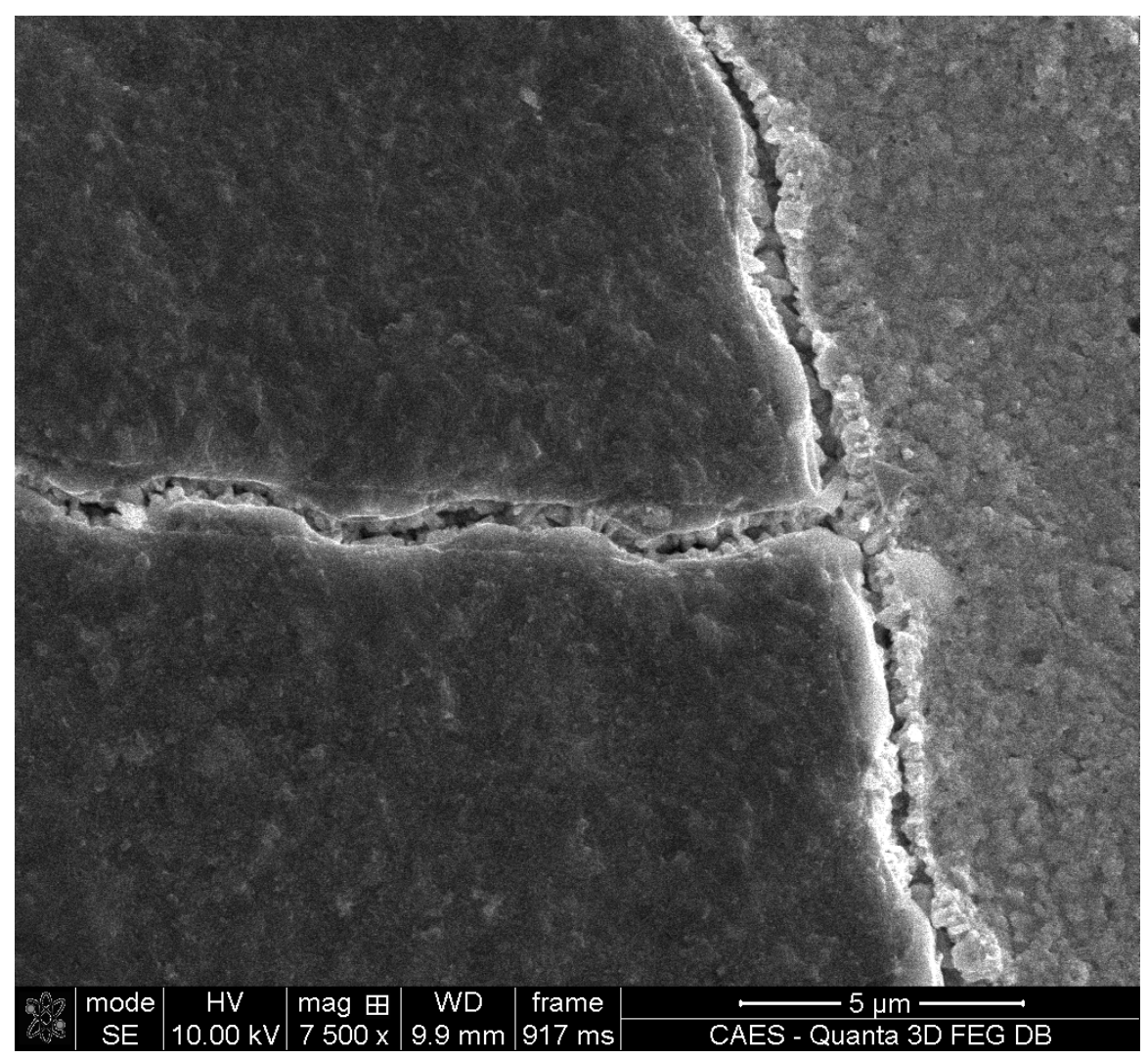

Figure 9. SEM image of the $\mathrm{Zr}-702$ tube broken edge magnified 7500X showing crack propagation in the tube.

\subsection{Bounding Safety Analysis}

Neutronic, thermal hydraulic and structural safety analyses are required for all experiments going into the ATR. Neutronics analysis is performed to identify the test assembly heat generation rate (HGR) profile, peak HGR (W/g), decay heat at shutdown, radionuclide source term (Curies) vs. time after shutdown, the ATR reactivity worth, and back-up test. A back-up test assembly determination is required to replace the experiment assembly in the event that the experiment cannot be inserted during a particular cycle. The back-up test reactivity worth must be equivalent to the experiment reactivity worth. Thermal hydraulics analysis is performed to determine the Departure from Nucleate Boiling Ratio (DNBR) during a flow coastdown scenario, the Flow Instability Ratio (FIR), the maximum temperature during operation, and the maximum experiment temperature after reactor shutdown for storage considerations. The structural analysis is performed to determine the structural stability of the experiment assembly during irradiation.

All safety analyses for the LWRS-1 non-fueled SiC CMC Zr-4 hybrid design were performed in 2011 to support the Experiment Safety Assurance Package ESAP. The results of the neutronics analysis documented in ECAR-1320 [10] showed that the experiment reactivity worth was significantly lower than the ATR limit of $\$ 0.25$ and that the maximum heat generation rate for any of the components is $2.44 \mathrm{~W} / \mathrm{g}$. Radionuclide data were calculated using a conservative assumption of $120 \mathrm{MW}$ core power and irradiation time of 194 days. A table of radionuclides at shutdown is listed in ECAR-1320. An aluminum filler was identified as the experiment back-up test. The thermal hydraulics analysis was conducted assuming a conservative lobe power of $34.18 \mathrm{MW}$ in the ATR I-23 position. The analysis is documented 
in ECAR-1317 [11]. The thermal analysis showed that the DNBR is 126.3 and the FIR is 10.6, both of which are significantly greater than the ATR minimum requirement of 2 . The maximum experiment flow coastdown was calculated at $180.5^{\circ} \mathrm{F}$ and the maximum temperature of free convection cooling air was calculated as $782.0^{\circ} \mathrm{F}$. Both temperatures are significantly lower than the melting point of Zircaloy and Al 6061 (basket material). The structural analysis results documented in ECAR-1301 [12] show that the tube and end caps of the SiC CMC Zr-4 hybrid design meet the intent of all relevant code requirements. The structural analysis assumed that the rodlet would not be fueled and would not generate pressures greater than $235 \mathrm{psig}$, therefore the rodlet was not analyzed as a pressure vessel per ASME Section III Class 1 code.

\subsubsection{Stress Analysis of Bonded vs. Non-bonded SiC CMC Zr-4 Tubes}

Due to the initial fabrication failure of the PIP bonded SiC CMC Zr-702 tubes, the program made a decision to continue with prototype testing of the hybrid design using non-bonded tubes until an adequate bonding technique could be developed. Thermal hydraulic analysis of the non-bonded tube confirmed that potential water penetration during irradiation testing between the inner and outer tubes would not negatively impact the thermal hydraulic performance. To determine the structural stability of a nonbonded rodlet during irradiation testing, preliminary structural analysis calculations were performed to compare stresses between the SiC CMC braided tube and the $\mathrm{Zr}-4$ inner tube for non-bonded and bonded rodlets. Preliminary structural analysis results showed that the difference in the coefficient of thermal expansion between the SiC CMC and the $\mathrm{Zr}-4$ affects the stress distribution in the two materials for the bonded case. Specifically, the axial stress in the Zr-based material is higher in the bonded case than in the non-bonded, as shown in Table 2 . These results are from an axisymmetric finite element model. The radial, axial, and hoop stresses are the result of the thermal gradient through the two materials and an external pressure of $468 \mathrm{psi}$. This configuration is for a non-fueled experiment.

Table 2. Comparison between axial stress in the Zr-based material and the SiC CMC material for the hybrid design non-fueled bonded and non-bonded capsules.

\section{Thermal and Pressure Stress}

\begin{tabular}{|c|c|c|c|c|}
\hline \multicolumn{5}{|c|}{ Unbonded - High Gap Conductance } \\
\hline & $\begin{array}{c}\text { R } \\
\text { Material }\end{array}$ & $\begin{array}{c}\text { Radial } \\
\text { Stress }\end{array}$ & $\begin{array}{c}\text { Axial } \\
\text { (inches) }\end{array}$ & $\begin{array}{c}\text { Hoop } \\
\text { (S11), psi }\end{array}$ \\
\hline (S22), psi & $\begin{array}{c}\text { Stress } \\
\text { (S33), psi }\end{array}$ \\
\hline zirc & 0.000 & -36 & -34 & -2518 \\
\hline zirc & 0.005 & -69 & -25 & -2475 \\
\hline zirc & 0.009 & -133 & -7 & -2393 \\
\hline zirc & 0.014 & -192 & 10 & -2317 \\
\hline zirc & 0.019 & -246 & 27 & -2246 \\
\hline zirc & 0.024 & -271 & 36 & -2212 \\
\hline cmc & 0.024 & -317 & -102 & -1932 \\
\hline cmc & 0.029 & -337 & -77 & -1886 \\
\hline cmc & 0.034 & -376 & -26 & -1798 \\
\hline cmc & 0.039 & -410 & 23 & -1714 \\
\hline cmc & 0.044 & -440 & 71 & -1635 \\
\hline cmc & 0.049 & -455 & 95 & -1597 \\
\hline
\end{tabular}

\section{Thermal and Pressure Stress}

\begin{tabular}{|c|c|c|c|c|}
\hline \multicolumn{5}{|c|}{ Bonded } \\
\hline Material & $\begin{array}{c}x \\
\text { (inches) }\end{array}$ & \begin{tabular}{|c|} 
Radial \\
Stress \\
(S11), psi \\
\end{tabular} & $\begin{array}{c}\text { Axial } \\
\text { Stress } \\
\text { (s22), psi }\end{array}$ & $\begin{array}{c}\text { Hoop } \\
\text { Stress } \\
\text { (S33), psi }\end{array}$ \\
\hline zirc & 0.000 & -45 & -2600 & -3179 \\
\hline zirc & 0.005 & -87 & -2591 & -3128 \\
\hline zirc & 0.009 & -168 & -2573 & -3029 \\
\hline zirc & 0.014 & -243 & -2556 & -2937 \\
\hline zirc & 0.019 & -311 & -2539 & -2852 \\
\hline zirc & 0.024 & -344 & -2530 & -2811 \\
\hline $\mathrm{cmc}$ & 0.024 & -387 & -679 & -1308 \\
\hline $\mathrm{cmc}$ & 0.029 & -398 & -653 & -1271 \\
\hline $\mathrm{cmc}$ & 0.034 & -419 & -602 & -1199 \\
\hline $\mathrm{cmc}$ & 0.039 & -438 & -553 & -1131 \\
\hline $\mathrm{cmc}$ & 0.044 & 454 & 505 & 1067 \\
\hline $\mathrm{cmc}$ & 0.049 & -461 & -481 & -1036 \\
\hline
\end{tabular}

For fueled experiments, unless the rodlet is encapsulated in an outer pressure boundary capsule, the rodlet would have to be re-analyzed to meet the intent of an ASME Section III Class 1 pressure vessel. Since Zircaloy and SiC CMC materials are not listed as ASME materials, prototype testing would be 
required to verify that the materials meet the intent of ASME Section III Class 1 pressure vessel code. A list of mechanical tests necessary to meet the intent of this code for fueled irradiation tests were identified by the structural analyst and are listed in Table 3 .

Table 3. Mechanical tests needed to support structural analysis of the SiC CMC Zr-4 hyrbid design fueled capsules to meet the intent of ASME Section III, Class 1 code.

\begin{tabular}{|l|l|l|}
\hline \multicolumn{1}{|c|}{$\begin{array}{c}\text { Failure Mode indentified by } \\
\text { ASME Code }\end{array}$} & \multicolumn{1}{|c|}{ ASME Code Provisions } & \multicolumn{1}{c|}{ Proposed Test } \\
\hline $\begin{array}{l}\text { Bursting and gross distortion from } \\
\text { a single load application }\end{array}$ & $\begin{array}{l}\text { Primary stress limits for } \\
\text { membrane and bending } \\
\left(\mathrm{P}_{\mathrm{m}}, \mathrm{P}_{\mathrm{b}} \text {, and } \mathrm{P}_{\mathrm{L}}\right)\end{array}$ & $\begin{array}{l}\text { a) Tensile test } \\
\text { b) Bend test } \\
\text { c) Internal pressure burst test }\end{array}$ \\
\hline $\begin{array}{l}\text { Progressive distortion from cyclic } \\
\text { load application }\end{array}$ & $\begin{array}{l}\text { Primary plus secondary stress } \\
\text { limits }(\mathrm{P}+\mathrm{Q})\end{array}$ & $\begin{array}{l}\text { Thermal distortion test where } \\
\text { the temperature is cycled }\end{array}$ \\
\hline $\begin{array}{l}\text { Crack initiation from fatigue } \\
\text { damage }\end{array}$ & Peak stress limits $(\mathrm{Sa})$ & $\begin{array}{l}\text { Pressure cycle testing at } \\
\text { temperature }\end{array}$ \\
\hline Instability & $\begin{array}{l}\text { Special stress limits for elastic } \\
\text { and inelastic instability }\left(\mathrm{P}_{\mathrm{a}}\right)\end{array}$ & $\begin{array}{l}\text { a) Compression test } \\
\text { b) External pressure test }\end{array}$ \\
\hline
\end{tabular}

\subsection{Design Review and ATR acceptance}

The final design review for the SiC CMC Zr-4 hybrid design was conducted in 2011 and ATR acceptance was obtained and documented in EJ-7.9.15-135 [13]. No significant concerns were addressed in the design review other than the need to perform prototype testing to ensure that fibers and/or pieces of the $\mathrm{SiC}$ CMC tube would not become dislodged from turbulent fluid flow past the tubes during irradiation testing, potentially impacting the ATR primary coolant flow and/or reactor safety. A requirement to perform prototype tests to support structural stability of the SiC CMC tube during high water flux and handling (i.e., high water flux and bend tests) was included in the ESAP.

\subsection{ATR Experiment Safety Assurance}

The ATR requires that an ESAP be prepared and approved prior to delivery of an experiment assembly to ATR for reactor insertion [14]. The ESAP addresses all aspects of an experiment testing or irradiation program from the arrival of the experiment at the ATR facility until the experiment leaves the ATR facility. The ESAP demonstrates that the experiment, experiment facility, experiment operation, and consequences of fault conditions comply with the ATR safety envelope as described in the Safety Assurance Report (SAR) and as implemented in the Technical Safety Report (TSR) [15]. The ESAP defines how the experiment will be handled in the ATR, the design analysis results, the control limits for the experiment, how the experiment will be irradiated, what positions in the ATR the experiment will be inserted, and how the experiment will be stored in the ATR canal and eventually be shipped for PIE. The ESAP also identifies how the experiment meets the SAR and TSR requirements for testing in the ATR. Although the existing LWRS ESAP envelopes the SiC CMC Zr-4 design, an ESAP for alternate cladding technologies could most likely be written based on the LWRS-1 ESAP with minor modifications to the design concept and design safety analysis results. The LWRS-1 ESAP was completed and approved in FY 2011 and is documented in ESAP-LWRS-1 [16] in the INL EDMS. 


\section{Sample Fabrication}

Samples fabricated for preliminary development testing should be characterized and understood at a level sufficient to assess the potential impact of material properties on desired performance to ensure that the data generated during this phase of the program accurately informs follow-on technology downselection and technology demonstrations. Quality requirements will be determined specifically for each end use application using a graded approach to define the required QA rigor. Samples developed for nonreactor applications may have different quality requirements than those requiring irradiation which will be included in the characterization test plans. . Similarly, later fueled experiments will likely require greater rigor and increased quality requirements compared to identical unfueled experiments due to the potential for generating internal pressures from fission gas release. Quality requirements may vary depending on end use; however, samples fabricated for non-nuclear testing must be fully representative of samples slated for irradiation testing to provide adequate baseline characterization measurements. All program participants must follow the requirements provided in the LWRS Quality Assurance Program Document (QAPD) [18]. Some participants may not have a QA program or be able to meet QA requirements for fabrication. The LWRS Program will allow use of these participants by accepting the materials through inspection and analysis and/or source inspection or a combination.

SiC CMC Zr-4 hybrid design mock-up samples were fabricated to support prototype test method development and equipment operability verification. Fabrication of Hot Water Corrosion Flow (HWCF) samples as well as bend test samples was accomplished using modified versions of drawing 602812. The bend test specimens were fabricated per 602812 except that the parts were all marked "mock-up" to prevent use of the parts in the ATR. These parts were representative to the parts that could be placed in the reactor except that the materials used were not certified for ATR use. The unintended side effect to the extra markings was that the tubes were etched in the middle portion of the tubes which may have had a negative effect on the performance of the parts. Future label instructions will be updated and included in the fabrication procedure. The HWCF samples were fabricated using drawing 602812 as a starting point; however, the Zircaloy tube was extended 11.5 inches and the second end cap was not attached. This allowed for the assembly to be installed in the aluminum basket in the HWCF system If desired, a pen heater can be inserted into the Zircaloy tube for testing with internal rod heating. Redline changes to drawing 602812 for fabrication of the HWCF mock-up samples are included in Appendix A.

Both the HWCF and bend test parts were fabricated using Zr-4 (UNS 60804) for the tubing and end caps. The SiC CMC tubes used were from the new fabrication techniques employed by PSI, where they are processed using an inert mandrel rather than using the Zircaloy tube. The protective sleeves that cover the ends of the $\mathrm{CMC}$ once installed on the Zr-4 tube were welded in place using a laser weld process. The end plug welds were performed in an inert gas environment (argon) using an orbital welder to produce an autogenous weld between the tube and end plug. The HWCF samples had a variety of laser markings all along the bare metal section of the tube, both in the regions of high flow and stagnant flow, to investigate the effects of the flow on the markings (see Appendix A).

Mock-up tests were performed using these samples to obtain a greater understanding of equipment operations and the prototype experiment processes (detail in 17). Once the equipment operability and experiment processes have been fully developed, prototype samples will be fabricated to perform prototype testing for ATR irradiation readiness per the LWRS ESAP requirements [16].

The prototype samples will be similar in design to the mock-up samples fabricated and are presented in this report as an example of the samples needed for prototype testing. Final design of the prototype samples are contingent on method development results. Photos of the fabricated mock-up samples are provided in Figure 10 and a list of the fabricated mock-up samples is included in Table 4 showing which samples were used for each test [17]. The bend test and hot water corrosion test mock-up 
samples were fabricated to INL drawing number 602812 (with red-line changes to the drawing to make the 18" long tubes). The green tags issued for the mock-up samples were for INL QL3 (supporting process development only); therefore, the results of the mock-up tests cannot be used for ATR readiness per the ESAP requirements (QL2 green tagged samples must be used to support ATR readiness).

LWRS-1-6-A-9: 2 PLY PIP processed SiC CMC Zr-4 hybrid tube used for Bend Test

LWRS-5-6-B-1: 1 PLY PIP processed $\mathrm{SiC}$ CMC Zr-4 hybrid tube used for Bend Test
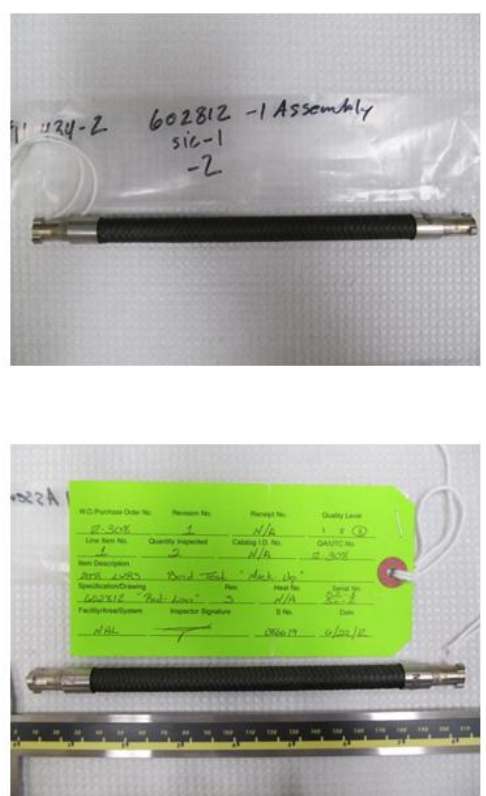

LWRS-1-6-A-8, 2-PLY PIP processed and LWRS-5-6-B-2, 1PLY PIP processed SiC CMC Zr-4 HWCF (low T) test samples along with $\mathrm{Zr}-4$ rod to be used as the standard

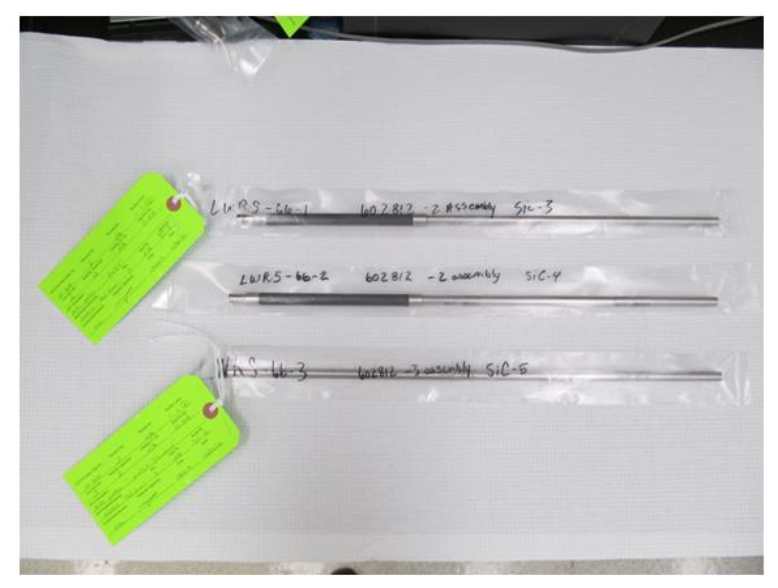

Figure 10. Photos of the SiC CMC Zr-4 hybrid design samples fabricated to support the Hot Water Corrosion Flow and bend tests. 
Table 4. List of samples fabricated for the bend tests and the Hot Water Corrosion Flow tests to support prototype testing development and equipment operability verification [17]. Green highlighted samples were used for pre-test characterization while pink highlighted samples were used for post-test characterization.

\begin{tabular}{|c|c|c|c|c|c|c|c|c|}
\hline \multirow[b]{2}{*}{$\begin{array}{c}\text { Original Sample } \\
\text { Description }\end{array}$} & \multirow[b]{2}{*}{$\begin{array}{c}\text { SiC-CMC } \\
\text { Fabrication }\end{array}$} & \multirow[b]{2}{*}{$\begin{array}{c}\text { QA } \\
\text { Label \& } \\
\text { Number }\end{array}$} & \multicolumn{2}{|c|}{$\begin{array}{c}\text { Pre-test } \\
\text { Characterization }\end{array}$} & \multicolumn{4}{|c|}{ Post-test Characterization } \\
\hline & & & $\begin{array}{c}\text { Visual \& } \\
\text { Dimension }\end{array}$ & $\begin{array}{l}\text { X- } \\
\text { ray }\end{array}$ & \begin{tabular}{|c|} 
Visual \& \\
Dimension
\end{tabular} & X-ray & SEM & Other \\
\hline \multicolumn{9}{|c|}{ BEND TEST } \\
\hline LWRS-1-6-A-2-3 & $\begin{array}{c}5 \text { cycles, } 2 \\
\text { ply }\end{array}$ & $\begin{array}{l}\text { Sleeve } \\
\text { only }\end{array}$ & $\mathrm{X}$ & $\mathrm{X}$ & $\mathrm{X}$ & $\mathrm{X}$ & $x$ & N/A \\
\hline LWRS-1-6-A-3-4 & $\begin{array}{c}5 \text { cycles, } 1 \\
\text { ply }\end{array}$ & $\begin{array}{c}\text { Sleeve } \\
\text { only }\end{array}$ & $\mathrm{X}$ & $\mathrm{X}$ & $\mathrm{X}$ & $\mathrm{X}$ & $x$ & N/A \\
\hline LWRS-1-6-A-6 & $\begin{array}{l}5 \text { cycles, } 1 \\
\text { ply }\end{array}$ & $\begin{array}{c}\text { Sleeve } \\
\text { only }\end{array}$ & $x$ & $x$ & $x$ & $x$ & $x$ & N/A \\
\hline LWRS-1-6-A-9 & $\begin{array}{c}7 \text { cycles, } 2 \\
\text { ply }\end{array}$ & SiC-1 & $\mathrm{x}$ & $\mathrm{X}$ & $\mathrm{X}$ & $\mathrm{X}$ & $x$ & $\mathrm{~N} / \mathrm{A}$ \\
\hline LWRS-5-6-B-1 & $\begin{array}{c}7 \text { cycles, } 1 \\
\text { ply }\end{array}$ & SiC-2 & $\mathrm{X}$ & $\mathrm{X}$ & $\mathrm{X}$ & $\mathrm{X}$ & $x$ & N/A \\
\hline Zr-4 assembled & $\mathrm{N} / \mathrm{A}$ & SiC-6 & $x$ & $x$ & $\mathrm{x}$ & $x$ & $x$ & $\mathrm{~N} / \mathrm{A}$ \\
\hline \multicolumn{9}{|c|}{ HOT WATER CORROSION FLOW TEST } \\
\hline LWRS-1-6-A-7 & $\begin{array}{c}7 \text { cycles, } 2 \\
\text { ply }\end{array}$ & Cracked & \multicolumn{2}{|c|}{ Visual \& SEM only } & N/A & $\mathrm{N} / \mathrm{A}$ & N/A & $\mathrm{N} / \mathrm{A}$ \\
\hline LWRS-1-6-A-8 & $\begin{array}{c}7 \text { cycles, } 2 \\
\text { ply }\end{array}$ & $\mathrm{SiC}-4$ & $\mathrm{x}$ & $\mathrm{x}$ & $\mathrm{x}$ & $\mathrm{x}$ & $x$ & $\begin{array}{c}\text { Water } \\
\text { analysis }\end{array}$ \\
\hline LWRS-5-6-B-2 & $\begin{array}{c}7 \text { cycles, } 1 \\
\text { ply }\end{array}$ & $\mathrm{SiC}-3$ & $\mathrm{x}$ & $\mathrm{X}$ & $\mathrm{X}$ & $\mathrm{X}$ & $\mathrm{X}$ & $\begin{array}{c}\text { Raman } \\
\text { TEM }^{*}\end{array}$ \\
\hline Zr-4 assembled & $\mathrm{N} / \mathrm{A}$ & $\mathrm{SiC}-5$ & $x$ & $\mathrm{x}$ & $\mathrm{X}$ & $\mathrm{X}$ & $\mathrm{X}$ & EBSD* \\
\hline \multicolumn{9}{|c|}{ BASELINE TESTS ON REPRESENTATIVE SAMPLES } \\
\hline $\begin{array}{l}\text { Original sample } \\
\text { description }\end{array}$ & \multicolumn{2}{|c|}{ SiC-CMC fabrication } & \multicolumn{6}{|c|}{ Characterization tests } \\
\hline $\begin{array}{l}\text { LWRS-1-6-A-7-1- } \\
2\end{array}$ & \multicolumn{2}{|c|}{7 cycles, 2 ply } & \multirow{4}{*}{\multicolumn{6}{|c|}{ Density }} \\
\hline $\begin{array}{l}\text { LWRS-1-6-A-9-1- } \\
2\end{array}$ & \multicolumn{2}{|c|}{7 cycles, 2 ply } & & & & & & \\
\hline $\begin{array}{l}\text { LWRS-1-6-B-2-1- } \\
2\end{array}$ & \multicolumn{2}{|c|}{7 cycles, 1 ply } & & & & & & \\
\hline LWRS-1-6-A-2-2 & 5 cycles & 2 ply & & & & & & \\
\hline $\begin{array}{l}\text { LWRS-1-6-A-7-1- } \\
1\end{array}$ & \multicolumn{2}{|c|}{7 cycles, 2 ply } & \multirow{4}{*}{\multicolumn{6}{|c|}{$\begin{array}{l}\text { XRD } \\
\text { SEM } \\
\text { Leach \& Chemical Analysis }\end{array}$}} \\
\hline $\begin{array}{l}\text { LWRS-1-6-A-9-1- } \\
1\end{array}$ & \multicolumn{2}{|c|}{7 cycles, 2 ply } & & & & & & \\
\hline $\begin{array}{l}\text { LWRS-1-6-B-2-1- } \\
1\end{array}$ & \multicolumn{2}{|c|}{7 cycles, 1 ply } & & & & & & \\
\hline LWRS-1-6-A-2-1 & \multicolumn{2}{|c|}{5 cycles, 2 ply } & & & & & & \\
\hline
\end{tabular}




\subsubsection{Material Certification and Traceability}

The INL ATR requires that experiment materials, with exception of trace constituents, in direct contact with the reactor primary coolant system (PCS) be known and identified as compatible materials prior to insertion for irradiation testing. Materials which are incompatible with the reactor fuel element cladding, the reactor primary coolant, canal water coolant, or with the reactor primary coolant system (PCS) structural materials must be contained to ensure they are not released to the PCS or canal. Unknown materials are not permitted in an ATR experiment [14].

The following are examples of materials which are chemically incompatible with the PCS: mercury, gold, copper, silver and chlorides. Gold, silver, or other properly reviewed materials may be used as activation monitors, provided they are secured so that the material cannot be lost into the reactor PCS. The preceding materials list is not all inclusive; there are other materials not listed that are incompatible with the reactor fuel element cladding [14].

All materials or components which come in contact with wetted surfaces of the ATR PCS or Loop PCS materials or which contact external portions of pressure boundaries shall be evaluated using the INL procedure SP-10.3.1.13, "Material Practices and Restrictions for ATR PCS and Experiment Loops" for guidance to eliminate detrimental effects from prohibited materials. This procedure identifies acceptable solvents and lubricants that can be used to clean materials to be inserted into the ATR, identifies prohibited and restricted materials, and provides guidance for leach testing materials to ensure that prohibited materials are not released into the PCS during irradiation testing [15]. Per this procedure, one sample shall be selected from each lot of non-metallic material for leach testing. In addition to PCS incompatible materials, the following materials must be identified prior to use [7]:

- hazardous chemicals that exceed the threshold quantities presented in 40 CFR 355 SARA and 29 CFR 1910.119 OSHA,

- hazardous chemicals that, if released, could pose a serious threat to the life and health of workers in the area, and

- radioactive materials that exceed the threshold quantities presented in 29 CFR 30.72 .

Materials procured from vendors not on the INL Qualified Suppliers List (QSL) were sampled and sent to an independent laboratory (on the INL QSL) for chemical analysis to support ATR safety requirements for insertion of only "known" materials. Traceability of the samples was maintained by storing in controlled storage locations while not in-process per LWP-2010 [20], labeling all samples appropriately per LWP-13120 [21], and keeping an inventory of all samples in an inventory database. An example of the database is shown in Figure 11. The database was developed by the LWRS fuels program to record and track raw materials, samples, sub-samples, and ATR experiment components. 


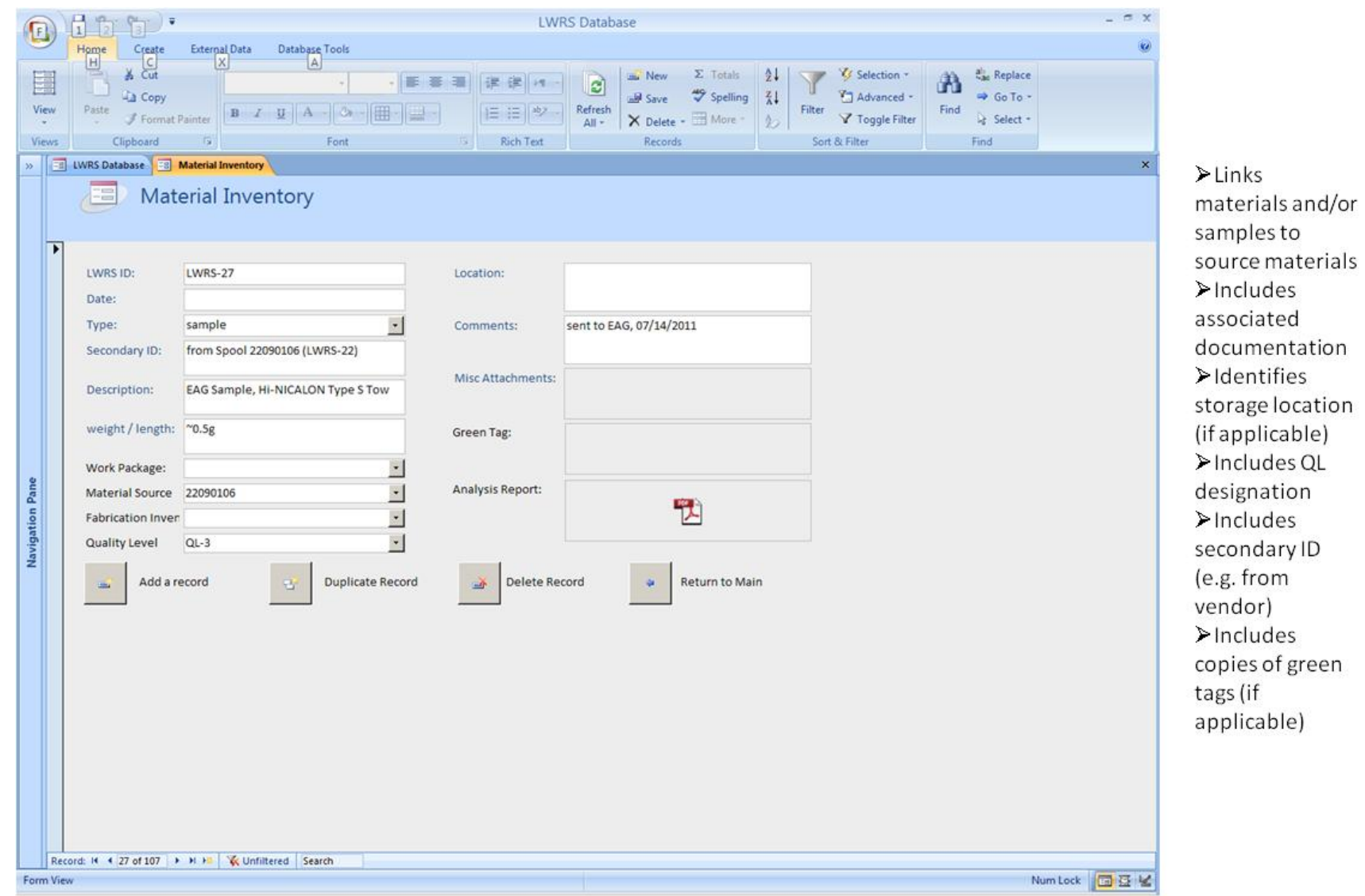

Figure 11. Example material inventory page from the LWRS Fuels Material Inventory Database.

\subsection{Development Testing and Characterization}

\subsubsection{Materials Characterization Techniques}

The primary objective of the cold characterization tests are to provide performance data on the cladding design, specifically the physical and chemical properties of the cladding and interactions to:

- form a baseline of pre-irradiated properties to support PIE

- perform prototype testing to support experiment design/development and in some instances to support irradiation readiness (i.e., corrosion flow tests, metallurgical examinations, visual inspections, bend tests, and leach tests)

The scientific data collected will be integrated to make a comparison between the conventional $\mathrm{Zr}-4$ cladding design and the proposed advanced cladding. An initial interpretation of the data will be used to provide confidence in the safe system performance and help guide the design process for later prototype design. The lessons learned will be used to guide the next suite of characterization tests.

Characterization tests planned to support ATR readiness are identified in PLN-3927 [22].

Prototype testing is planned to characterize performance of the cladding design in the intended cylindrical geometry in appropriate environment conditions. Prototype testing will also be used as a risk mitigation tool for irradiation readiness. Specific operational prototype tests discussed in the following sections will 
be used to measure rodlet corrosion under flowing water conditions, thermal cyclic behavior, bend performance, and reaction to a steam environment (simulating LOCA conditions).

The cold (i.e., unirradiated) characterization tests are organized according to two classifications, namely "prototype" and "baseline," as shown in Figure 12. Tests are further grouped into "nondestructive" and "destructive" activities. The example characterization test plan shown in Figure 12 [22] was developed specifically for a candidate SiC-CMC/Zircaloy-4 hybrid cladding tube. While many of the characterization measurements or tests can be translated to alternate cladding designs (i.e. fully ceramic $\mathrm{SiC}-\mathrm{SiC}$ cladding), some are specific to the hybrid design and would require replacement with the appropriate test or standard for an alternate design.

The characterization tests listed in Figure 12 will help demonstrate the following advantageous properties of the proposed designs [22]:

- High strength at temperature to help mitigate accident scenarios.

- Low chemical reactivity of $\mathrm{SiC}$ to reduce the rapid exothermic reaction between the clad and high temperature water / steam that generates hydrogen, relative to zirconium-based cladding.

- The lower neutron cross section has the potential to improve nuclear fuel economics by reducing parasitic capture in the cladding.

- Reduced embrittlement and improved radiation stability, increasing fuel lifetimes compared to zirconium.

- Cladding hardness and dimensional stability, which will decrease fretting susceptibility.

A specific characterization plan will be written for each fuel cladding system technology being tested to describe the methods, data collection parameters, and uncertainties of the tasks specified for characterization activities. The characterization plan will identify specific test plans or procedures to be followed and the frequency and proposed acceptance criteria for each of the tests, with reference to ASTM standards and codes as applicable. The specific acceptance criteria for each test will be included in the final QA inspection plan. An example characterization plan is provided in Figure 12 identifying each of the tests proposed in the sample characterization plan. 


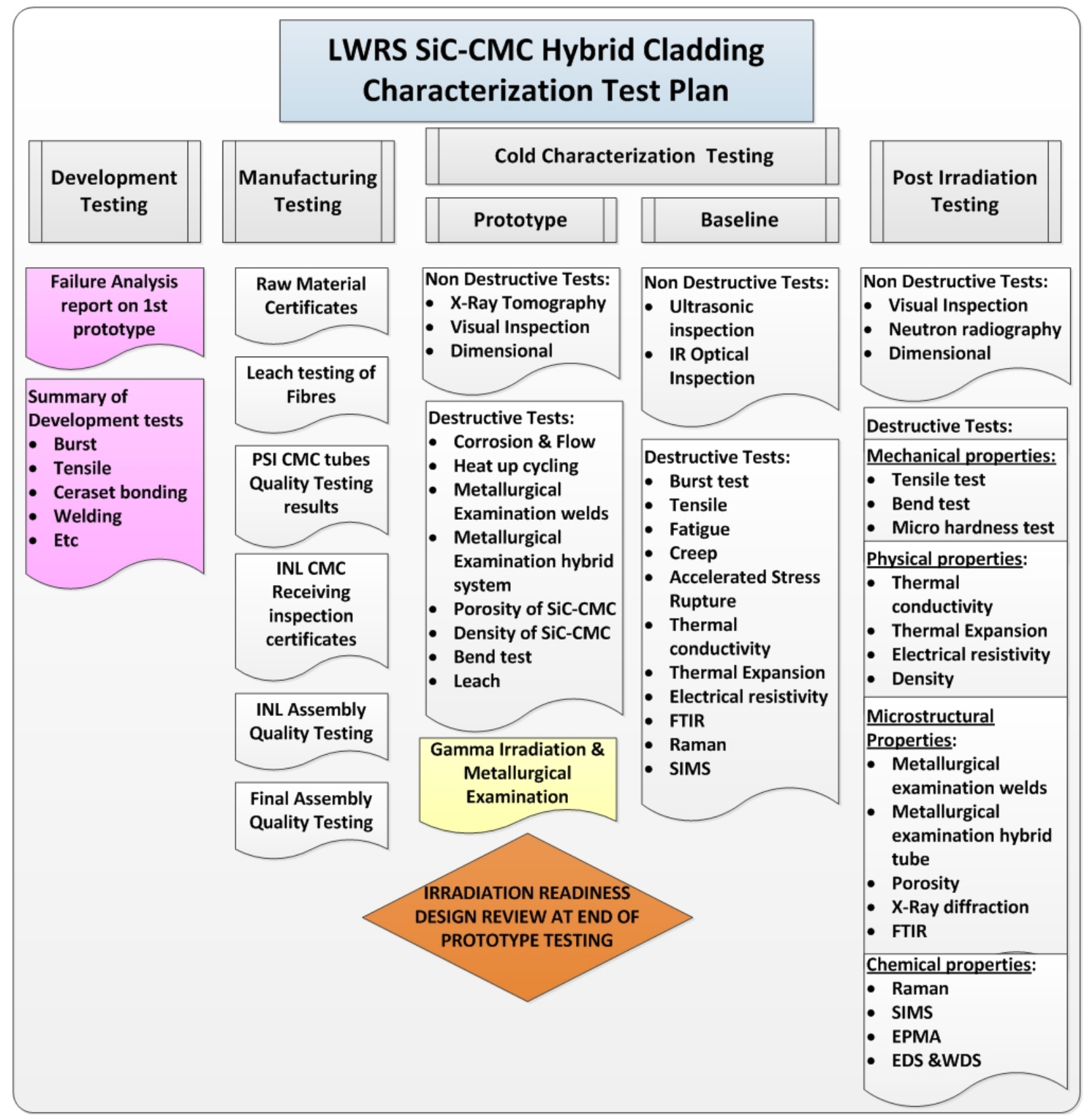

Figure 12. Example of test classifications to be performed on fuel cladding system technologies examined under the LWRS Program. This example classification was designed specifically for a hybrid $\mathrm{SiC} \mathrm{CMC}$ design; however, it can be used as a template for alternate technologies [22].

\subsection{Fuel Performance Modeling}

Prototype testing/development, fuel performance modeling, and experiment design analysis are all iterative integrated processes that work together to refine the experiment design. The computational modeling effort for fuel performance modeling in the LWRS program is heavily dependent on larger computational modeling efforts supported by DOE-NE. Primary code development efforts are performed under the Nuclear Energy Advanced Modeling and Simulation (NEAMS) and Consortium for Advanced 
Simulation of Light Water Reactors (CASL) hubs. NEAMS supports the development of the BISON and MARMOT codes used to model conventional nuclear fuel. These codes work across multiple scales and can include multiple physics models, allowing for multiscale simulation of fuel and nuclear materials and how they interact. MOOSE (Multiphysics Object-Oriented Simulation Environment) is the top-level architecture that integrates the BISON engineering scale fuel performance code and the MARMOT mesoscale fuels code. The CASL hub works directly with commercial reactor operators and can provide a virtual reactor to evaluate the performance of advanced nuclear fuel designs. The ability to evaluate full core fuel performance will greatly assist the development of advanced nuclear fuel [2].

\subsection{Irradiation Testing}

LWRS-1 non-fueled experiment assemblies will begin irradiation in the ATR I-23 (small I) position after the selected cladding technologies have been fully developed, characterized and prototype tested to support ATR insertion readiness. LWRS-2 fueled experiments were initially planned for irradiation in the ATR B-9 (large B) position using the same cladding technology as LWRS-1; however, the fueled tests will not be performed for several years and, therefore, the ATR positions will be determined once the LWRS-1 experiments have been completed. The irradiation time will range from single cycles to the maximum burn-up achieved in a commercial LWR. Experiment arrays using longer rod lengths are being considered for future irradiation tests. The array tests will require additional engineering design and analyses to account for longer rod length and irradiation conditions in a medium I position (ATR position contingent on scoping analysis). Each fueled irradiation experiment is expected to continue for approximately 4-5 years depending on experiment objectives.

\subsubsection{Reactor Description}

The ATR was designed to provide large-volume, high-flux test locations. A unique serpentine fuel arrangement, as shown in Figure 13, provides nine high-intensity neutron flux traps and 68 additional irradiation positions inside the reactor core reflector tank, each of which can contain multiple experiments. The ATR is the most powerful research reactor operating in the U.S. and has larger test volumes in high flux regions than any other reactor. 


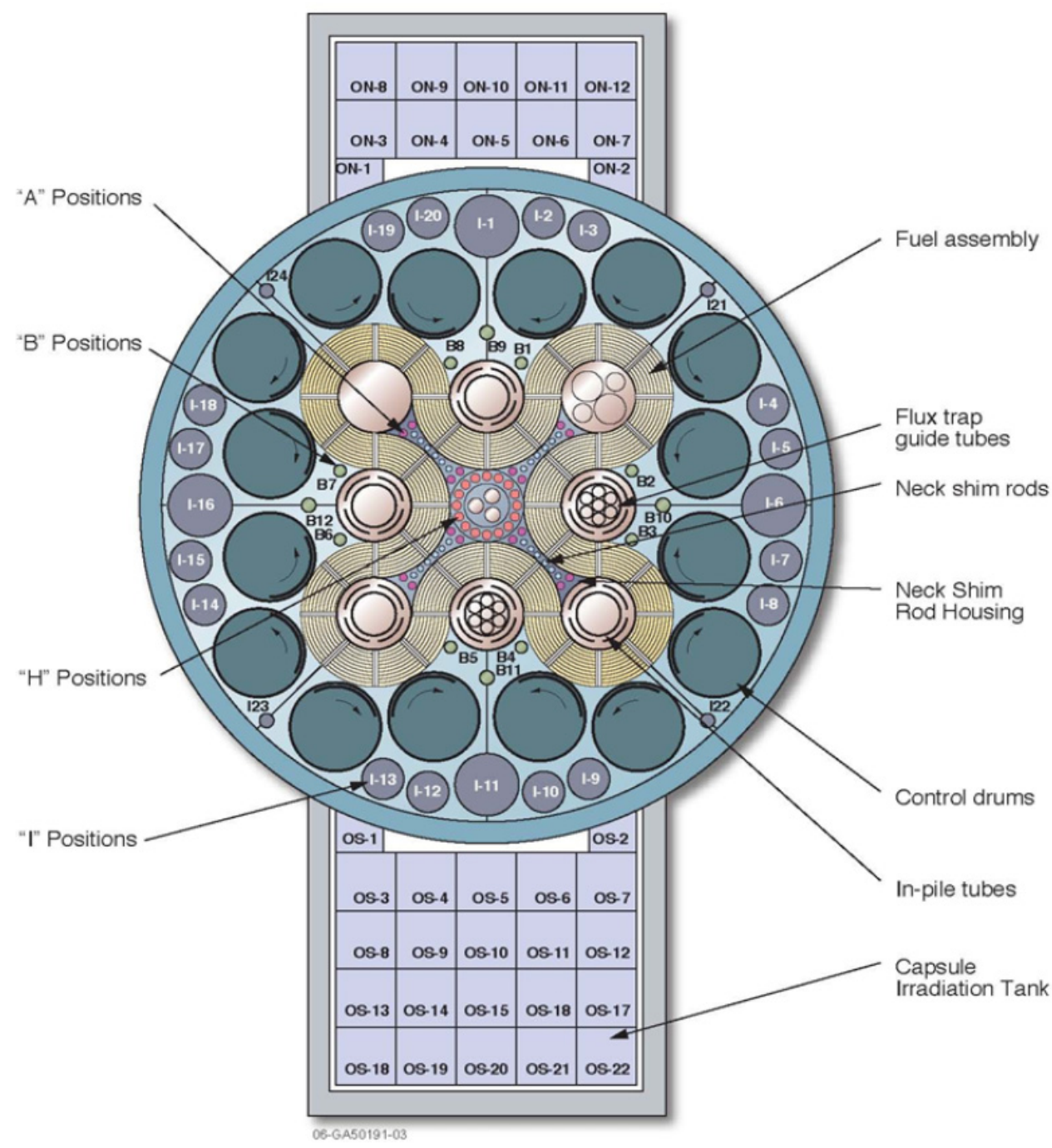

Figure 13. ATR core cross sectional diagram [23].

General characteristics of the ATR are listed in Table 5. The ATR's unique control device design permits large power shifts among the nine flux traps. The ATR uses a combination of control cylinders or drums and neck shim rods. The control cylinders rotate hafnium plates toward and away from the core; the shim rods, which withdraw vertically, are individually inserted or withdrawn to adjust power. Within bounds, the power level in each corner lobe of the reactor can be controlled independently. 
Table 5. ATR General Characteristics [23].

\begin{tabular}{|c|c|}
\hline \multicolumn{2}{|l|}{ Reactor } \\
\hline Thermal Power & $250 \mathrm{MW}_{\mathrm{th}} \mathrm{l}^{\mathrm{a}}$ \\
\hline Power Density & $1.0 \mathrm{MW} / \mathrm{L}$ \\
\hline Maximum Thermal Neutron Flux & $1.0 \times 10^{15} \mathrm{n} / \mathrm{cm}^{2}-\mathrm{sec}^{\mathrm{b}}$ \\
\hline Maximum Fast Flux & $5.0 \times 10^{14} \mathrm{n} / \mathrm{cm}^{2}-\mathrm{sec}^{\mathrm{b}}$ \\
\hline Number of Flux Traps & 9 \\
\hline Number of Experiment Positions & 62 \\
\hline \multicolumn{2}{|l|}{ Core } \\
\hline Number of fuel assemblies & 40 \\
\hline Active length of Assemblies & $1.2 \mathrm{~m}$ \\
\hline Number of fuel plates per assembly & 19 \\
\hline Uranium- 235 content of an assembly ${ }^{\circ}$ & $1,075 \mathrm{~g}$ \\
\hline Total core load ${ }^{\mathrm{C}}$ & $43 \mathrm{~kg}$ \\
\hline \multicolumn{2}{|l|}{ Coolant } \\
\hline Design Pressure & $2.7 \mathrm{MPa}$ \\
\hline Design Temperature & $115^{\circ} \mathrm{C}$ \\
\hline Reactor coolant & Light water \\
\hline Maximum Coolant Flow Rate & $3.09 \mathrm{~m}^{3} / \mathrm{s}$ \\
\hline Coolant Temperature (Operating) & $<52{ }^{\circ} \mathrm{C}$ inlet, $71{ }^{\circ} \mathrm{C}$ outlet \\
\hline $\begin{array}{l}\text { a. Maximum design pow er. ATR is seldom operat } \\
\text { b. These parameters are based on the full } 250 \mathrm{M} \\
\text { c. At beginning of Ife. }\end{array}$ & onally reduced for lower reactor pow er levels. \\
\hline
\end{tabular}

\section{Discussion/Conclusions}

The irradiation testing readiness process was identified in this report for drop-in capsule experiments to be performed in the ATR. Steps taken in preparation for ATR experiments of the SiC CMC Zr-4 hydrid design were presented as an example and lessons learned for future cladding technology experiments. For the $\mathrm{SiC} \mathrm{CMC} \mathrm{Zr-4} \mathrm{hybrid} \mathrm{design,} \mathrm{the} \mathrm{design} \mathrm{analysis,} \mathrm{design} \mathrm{review,} \mathrm{and} \mathrm{safety}$ analysis has been completed for non-fueled, non-bonded cladding tubes (inner $\mathrm{Zr}-4$ and $\mathrm{SiC} \mathrm{CMC}$ outer overbraid tube). Mock-up tests are currently being conducted for process development and equipment operability in preparation for prototype tests required to support ATR readiness for the hybrid design cladding technology. Additional tasks to be completed prior to ATR testing of the non-fueled hybrid design include:

- Implementation of the findings of the mock-up sample testing, specifically upgrade of HWCF system

- Prototype sample fabrication (pedigree samples - QL2 green tagged)

- Characterization of prototype samples

- Baseline characterization of representative prototype samples

- Non destructive testing of actual prototypes ( tomography, visual inspections, dimensional measurements)

- Hot water corrosion flow tests using prototype samples, inclusive of pre- and post testing characterization as determined in [17] 
- Bend tests using prototype samples inclusive, of pre- and post testing characterization as determined in [17]

- Porosity and density measurements of SiC CMC tubes (for each batch to be used in ATR irradiation tests)

- Leach testing of the SiC CMC tubes (for each batch to be used in ATR irradiation tests)

- Independent chemical analysis of the $\mathrm{SiC} \mathrm{CMC} \mathrm{and} \mathrm{Zr}-4$ tubes (for each batch to be used in ATR irradiation tests)

Additional testing and analysis to be performed prior to fueled drop-in capsule irradiation testing of the $\mathrm{SiC}$ CMC Zr-4 hybrid design include:

- Complete thermal and structural analysis of the bonded tube design

- Selection and prototype testing of a bonding agent to bond the SiC CMC tubes to the $\mathrm{Zr}-4$ inner tube

- A series of mechanical tests (outlined in Table 2) to support structural analysis of the hybrid design capsule to meet the intent of ASME Section III, Class 1 pressure vessel.

\section{References}

1. Barrett, K. E., S. Bragg-Sitton, D. Galicki, 2012, Advanced LWR Nuclear Fuel Cladding System Development Trade-Off Study, INL/EXT-12-27090, INL external report.

2. Bragg-Sitton, S., Advanced LWR Nuclear Fuel Cladding System Development Technical Program Plan, INL/MIS-12-25696, LWRS program plan.

3. Garnier, J. E. and G. W. Griffith, Cladding Material, Tube Including Such Cladding Material and Methods of Forming the Same, INL Invention Disclosure, IDR \# BA-477, 2010.

4. Idaho National Laboratory, Nuclear Materials Experiments Life-Cycle Process, LWP-10700, INL Laboratory Wide Procedure.

5. Barrett, K. E., , Project Execution Plan For The Light Water Reactor Sustainability (LWRS) Advanced LWR Nuclear Fuel Development Pathway Experiments In The ATR, PLN-3971, LWRS internal project document.

6. Idaho National Laboratory, Document Management, LWP-1201, INL Laboratory Wide Procedure.

7. Barrett, K. E., Research and Development Drop-In Capsule Advanced Test Reactor Irradiation Experiment For The Light Water Reactor Sustainability (LWRS) Non-Fueled Cladding Experiments, TFR-731, INL Technical and Functional Requirements Document.

8. Idaho National Laboratory, ATR Isotope Production and Experiment Basket Elevations, DWG447942, INL internal drawing. . 
9. Glass, C. R., LWRS Scoping Analysis Summary, INL Interoffice Memo, Glass Letter File CRG-012011, Rev. 0 (2011).

10. Glass, C. R., LWRS-1 PHYSICS ANALYSIS, ECAR-1320 Rev. 2, INL Experiment Calculations and Analysis Report.

11 Roth, G. A., LWRS-1 THERMAL EVALUATION, ECAR-1317 Rev. 0, INL Experiment Calculations and Analysis Report.

12 Ellis, K. D., Structural Analysis of LWRS-1 Capsule Experiment, ECAR-1301 Rev. 1, INL Experiment Calculations and Analysis Report.

13. Idaho National Laboratory, LWRS-1 Experiment Design, EJ-7.9.15.135, INL Engineering Job.

14. Idaho National Laboratory, Capsule Irradiation Facilities, SAR-153, Chapter 10, Section 10.3, INL Advanced Test Reactor Safety Analysis Report.

15. Idaho National Laboratory, Experiment Safety Assurance Package Preparation And Approval, SP10.6.2.1 Rev. 28, INL Standard Practices.

16. Idaho National Laboratory, Experiment Safety Assurance Package For the LWRS-1 Experiment In The Advanced Test Reactor, ESAP-LWRS-1, INL Advanced Test Reactor Experiment Safety Assurance Package.

17. Van Rooyen, I. J., Pre-Irradiation Testing and Analysis to Support the LWRS Hybrid SiC-CMCZircaloy-4 Unfueled Rodlet Irradiation, INL/EXT-12-27189, INL external report, September 2012.

18. Jensen, D. K.,, Light Water Reactor Sustainability Quality Assurance Program Document, INL/EXT10-19844, INL external document.

19. Idaho National Laboratory, Material Practices and Restrictions For ATR PCS And Experiment Loops, SP-1.3.1.13, INL Standard Practices.

20, Idaho National Laboratory, Storing Government Property, LWP-2010, INL Laboratory Wide Procedure.

21. Idaho National Laboratory, Identifying and Controlling Items, LWP-13120, INL Laboratory Wide Procedure.

22. Van Rooyen, I., J., Cold Characterization Plan For LWRS-1 Hybrid SIC-CMC Zircalloy-4 Experiments, PLN-3927 Rev. 0, LWRS project plan.

23. Idaho National Laboratory, FY 2009 Advanced Test Reactor National Scientific User Facility User's Guide, INL/EXT-08-14709, INL external document. 


\section{Appendices}

Appendix A: Redline drawing changes used for fabrication of the Hot Water Corrosion Flow mock-up samples. 


\section{Appendix A}

Redline Drawing Changes Used for Fabrication of the Hot Water Corrosion Flow Mock-up Samples

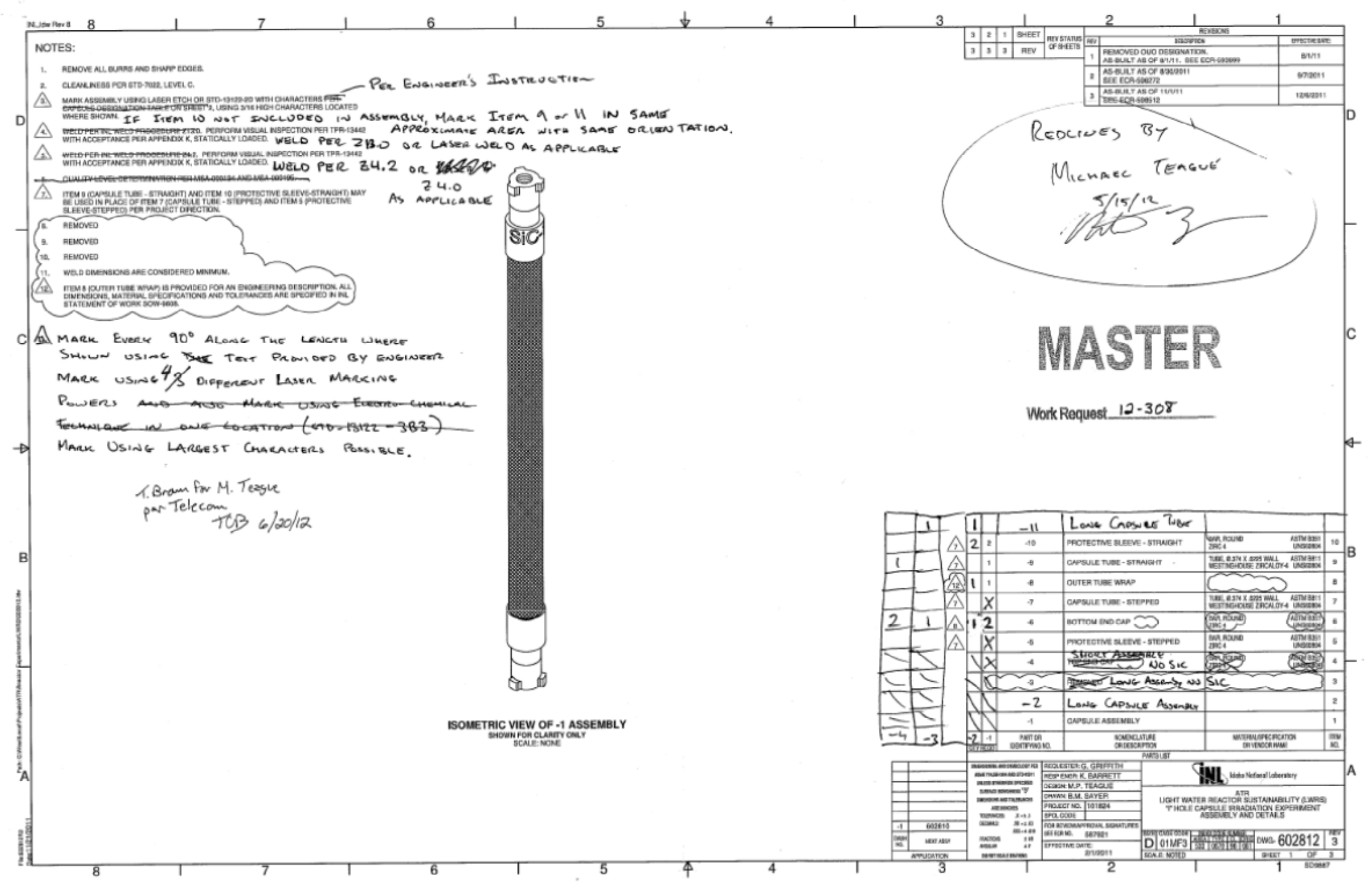




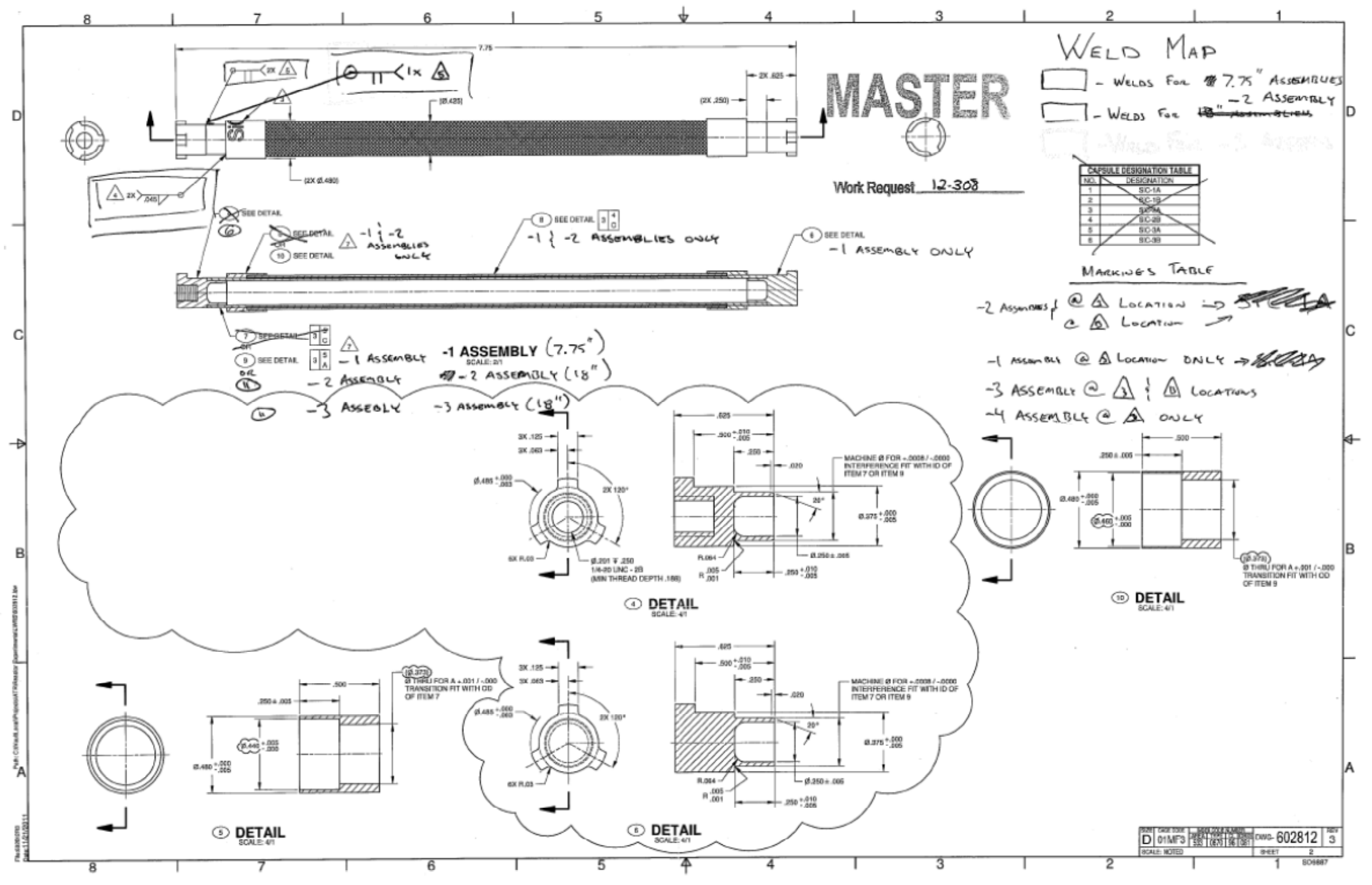




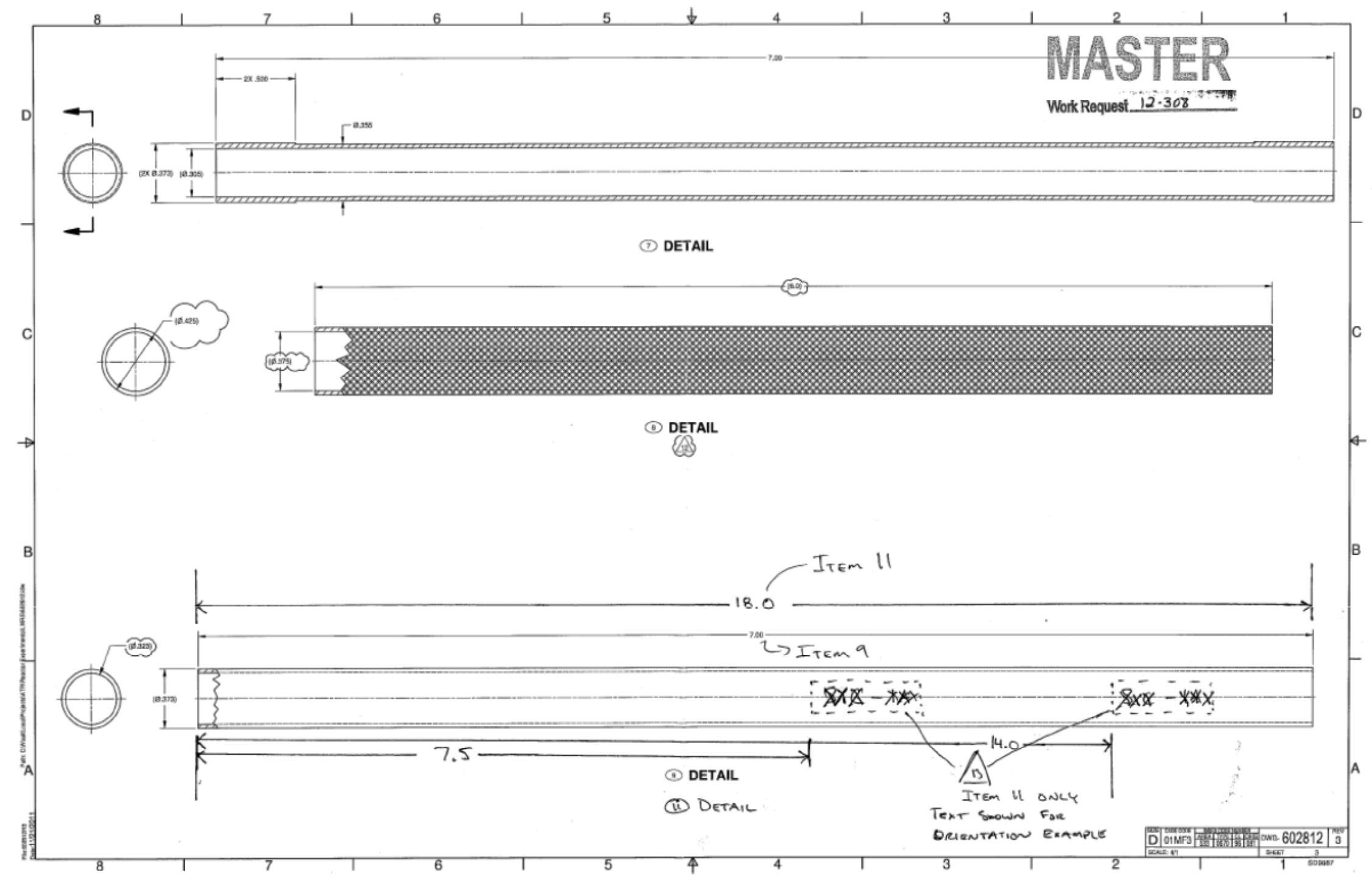

